\title{
Advances in Instrumental Analysis of Brominated Flame Retardants: Current Status and Future Perspectives
}

\author{
Mohamed Abou-Elwafa Abdallah ${ }^{1,2}$ \\ ${ }^{1}$ Division of Environmental Health and Risk Management, School of Geography, Earth and Environmental Sciences, \\ University of Birmingham, Birmingham B15 2TT, UK \\ ${ }^{2}$ Department of Analytical Chemistry, Faculty of Pharmacy, Assiut University, Assiut 71526, Egypt
}

Correspondence should be addressed to Mohamed Abou-Elwafa Abdallah; mae_abdallah@yahoo.co.uk

Received 27 April 2014; Accepted 14 July 2014; Published 29 October 2014

Academic Editor: María Teresa Tena

Copyright (c) 2014 Mohamed Abou-Elwafa Abdallah. This is an open access article distributed under the Creative Commons Attribution License, which permits unrestricted use, distribution, and reproduction in any medium, provided the original work is properly cited.

\begin{abstract}
This review aims to highlight the recent advances and methodological improvements in instrumental techniques applied for the analysis of different brominated flame retardants (BFRs). The literature search strategy was based on the recent analytical reviews published on BFRs. The main selection criteria involved the successful development and application of analytical methods for determination of the target compounds in various environmental matrices. Different factors affecting chromatographic separation and mass spectrometric detection of brominated analytes were evaluated and discussed. Techniques using advanced instrumentation to achieve outstanding results in quantification of different BFRs and their metabolites/degradation products were highlighted. Finally, research gaps in the field of BFR analysis were identified and recommendations for future research were proposed.
\end{abstract}

\section{Introduction}

Flame retardants are a diverse group of chemicals added to a wide range of consumer products, including plastics, polymers, textiles, building materials, and electric and electronic equipment, to prevent or delay the propagation of fire. Currently, there are 4 major groups of flame retardants on the market: inorganic, halogenated organic, organophosphorus, and nitrogen based compounds. Brominated flame retardants (BFRs; a subgroup of the halogenated organic class) are currently the largest market group of flame retardants due to their low cost and high performance efficiency [1]. In 2006, the total consumption of flame retardants in Europe was $465000 \mathrm{t}$, of which $10 \%$ were BFRs [2]. There are 75 different commercial BFRs, each with specific properties depending on the nature of the material they are protecting. Some BFRs are reacted (i.e., chemically-bonded) into the final polymer while most of them are used as additives to the polymer matrix. Available figures show the most widely used BFRs are tetrabromobisphenol A (TBBP-A) with a global demand of 170,000 tonnes in 2004, alongside decabromodiphenyl ether (Deca-BDE), hexabromocyclododecane (HBCD), pentabromodiphenyl ether (Penta-BDE), and octabromodiphenyl ether (Octa-BDE), for which worldwide market demands in 2001 were 56,100, 16,700, 7,500, and 3,790 tonnes, respectively [3]. Since polybrominated diphenyl ethers (PBDEs) and HBCD (and $\sim 20 \%$ of the production of TBBP-A) are blended physically rather than bonded chemically to polymeric materials, they migrate into the environment where their persistence and bioaccumulative characters lead to contamination of humans [4]. This is of concern owing to the potential health risks associated with human exposure to these compounds including endocrine disruption, neurodevelopmental, and behavioural disorders, hepatic abnormality, and possibly cancer $[5,6]$. The few data available from human epidemiological studies imply effects on male reproductive hormones [7], semen quality [8], thyroid hormone homeostasis [9], and cryptorchidism [10], as well as lower birth weight and length [11]. Such evidence has contributed to complete EU bans for Penta and OctaBDE, and restrictions on the use of DecaBDE in addition to other restrictions within severaljurisdictions 
on the manufacture and new use of the three commercial PBDE formulations across the world [4]. Moreover, HBCD and PBDEs associated with Penta and OctaBDE have been listed under the UNEP Stockholm Convention on POPs, while DecaBDE is currently under consideration for listing under Annexes A, B, and/or C to the convention [12]. Despite such restrictions, human exposure to BFRs is likely to continue for the foreseeable future, given their persistence and ubiquity of flame-retarded products in the environment [13]. Furthermore, the restrictions on the production and usage of HBCD and PBDEs have paved the way for development and application of "novel" BFRs as replacements for the banned formulations. Important representatives of this NBFR group are decabromodiphenyl ethane (DBDPE), 1,2bis(2,4,6-tribromophenoxy)ethane (BTBPE), 2-ethylhexyl2,3,4,5-tetrabromobenzoate (TBB), and bis(2-ethylhexyl)3,4,5,6-tetrabromo-phthalate (TBPH) (Table 1). While more information, especially regarding their toxicological profile, is required to define the fate and transport characteristics of NBFRs, the current state-of-knowledge on the production, usage, environmental occurrence, persistent $(\mathrm{P})$, bioaccumulative (B), and toxic (T) characteristics of various NBFRs was recently reviewed [14]. Against the continuously increasing scientific interest in the environmental fate, behavior, and human health implications of the currently ubiquitous BFRs, one of the major trends in analytical chemistry is efficient determination of the trace levels of various BFRs in complex matrices [15]. Different aspects related to production, usage, environmental occurrence, toxicity, and human exposure to different BFRs have been recently reviewed [14, 16-20]. Therefore, the aims of this work are (a) to provide a critical review of the recent analytical techniques applied for the analysis of various classes of BFRs in different environmental and biological matrices and (b) to discuss the current challenges in the field of BFR analysis and provide recommendations for future research in this field.

\section{Sample Preparation for BFR Analysis}

Understanding the physicochemical properties of pollutants is pivotal to study their fate and behaviour in both indoor and outdoor environments. To this end, BFRs display a wide range of physicochemical properties depending on their molecular structure and weight (Table 1). The large variety in molecular weight, polarity, vapour pressure, and $\log K_{\text {ow }}$ displayed by different classes of BFRs is associated with varying degrees of environmental mobility, long-range transport, persistence, bioaccumulation, and toxicity [21]. Furthermore, the diversity in physicochemical parameters displayed by BFRs represents a continuous challenge for analytical chemists aiming to develop multiresidue methods for their analysis. Therefore, several methods were reported for exhaustive extraction and clean-up of different BFRs from both biotic and abiotic environmental matrices. Advances in sample preparation techniques for analysis of BFR in environmental matrices have been recently reviewed [22]. Hence, sample preparation techniques are not the focus of the current paper and will only be briefly summarized in Tables 2 and 3.

\section{Instrumental Analysis of BFRs}

Due to their diverse nature, wide range of physicochemical properties, large number of congeners and relatively low concentrations in various matrices, chromatographic separation hyphenated with mass spectrometric detection techniques are generally the method of choice for analysis of different BFRs in biotic and abiotic matrices.

3.1. GC/MS Analysis. GC/MS is the most commonly used technique for analysis of BFRs [54]. Thermal degradation and isomeric interconversion are the main challenges facing analytical chemists with the GC/MS analysis of BFRs. Therefore, several parameters of the GC/MS system need to be carefully optimised according to the properties of target analytes. These include injection technique, stationary phase, column dimensions, and mass spectrometric parameters.

3.1.1. Sample Injection. Because of their relatively low levels in most matrices, the most common injection techniques applied for BFR analysis are splitless injection, on-column injection, and programmed temperature vaporisation (PTV) [55]. In addition to its low cost and availability as a standard feature for most GC/MS instruments, splitless injection is favoured by several analysts due to the expected trace levels of BFRs in most environmental samples. However, thermal degradation and mass discrimination of higher molecular weight compounds are main drawbacks of this technique [56]. Therefore, injector temperature and splitless time need to be optimised for maximum sensitivity. For instance, highest possible temperature and long splitless time $\left(325^{\circ} \mathrm{C}\right.$ for $4 \mathrm{~min}$ ) resulted in an increased response factor of BDE-209 [57]. An alternative way to minimize thermal degradation in the injector/liner section of the instrument is direct oncolumn injection. In this technique, the injected sample is delivered directly to the entrance of the capillary column resulting in higher precision and less variability of the results [58]. However, extensive sample clean-up is required to prevent matrix-related interfering substances and macromolecular residues from reaching the column which may cause peak tailing, high noise levels, retention time shifts, and eventually shorten the column lifetime [57]. Recently, PTV injection emerged as the method of choice for multiresidue analysis of different classes of BFRs and NBFRs in the same sample. PTV can provide several advantages including minimal degradation of thermolabile contaminants, reduced thermal discrimination of high molecular weight compounds, large injection volumes, and improved response factor of higher molecular weight PBDEs $[34,59,60]$.

3.1.2. Stationary Phase and GC Column Dimensions. The elution order of 126 PBDE congeners was determined and compared on 7 different GC column stationary phases [61]. The most suitable stationary phase for efficient separation of PBDE congeners was DB-XLB (J\&W Scientific) followed closely by DB-1 (J\&W Scientific) column. However, the latter is usually preferred for routine PBDE analysis due to reduced degradation of higher brominated congeners. For NBFRs, low polarity stationary phases were generally used for their separation. The most commonly reported stationary phase 


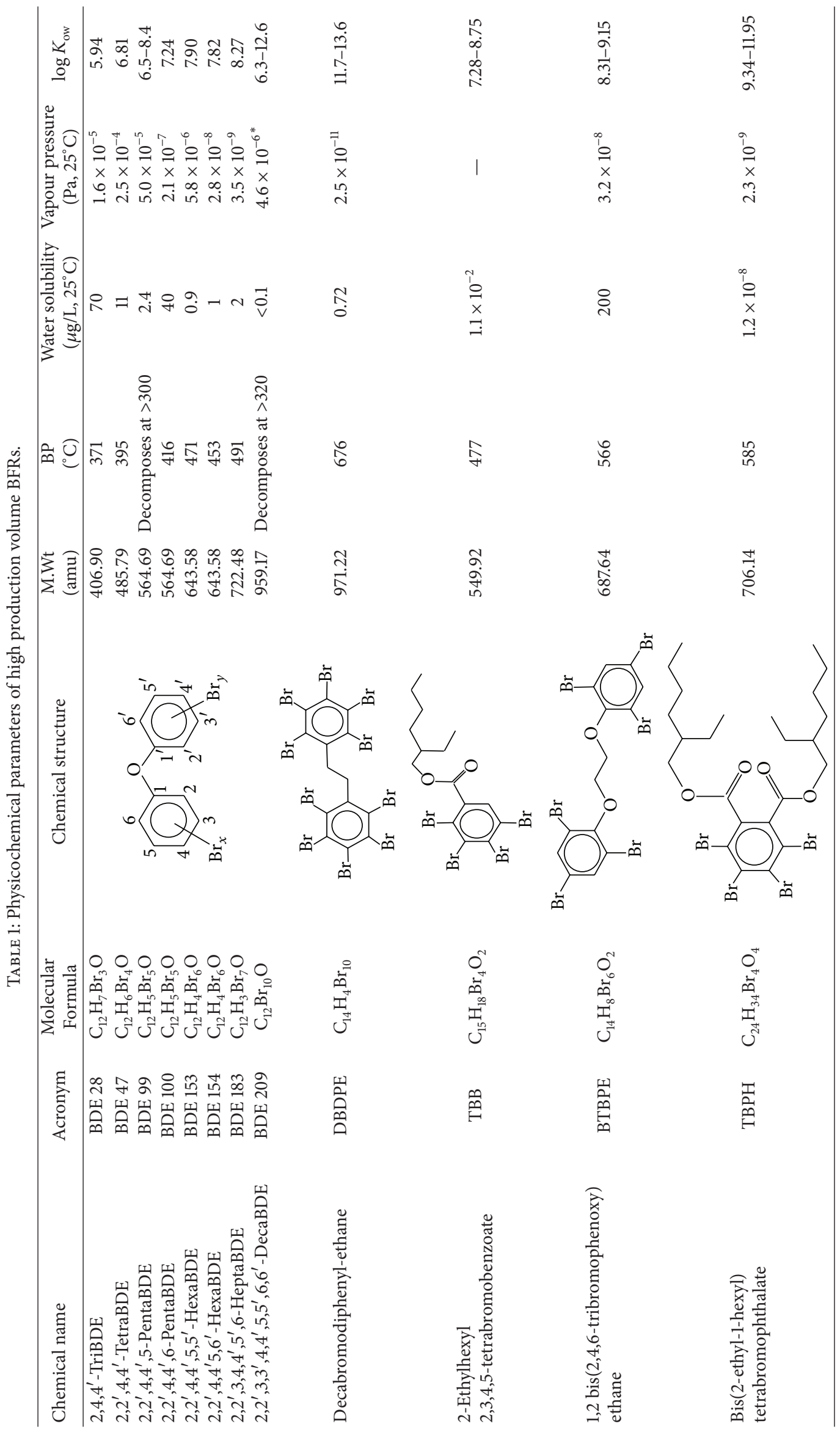




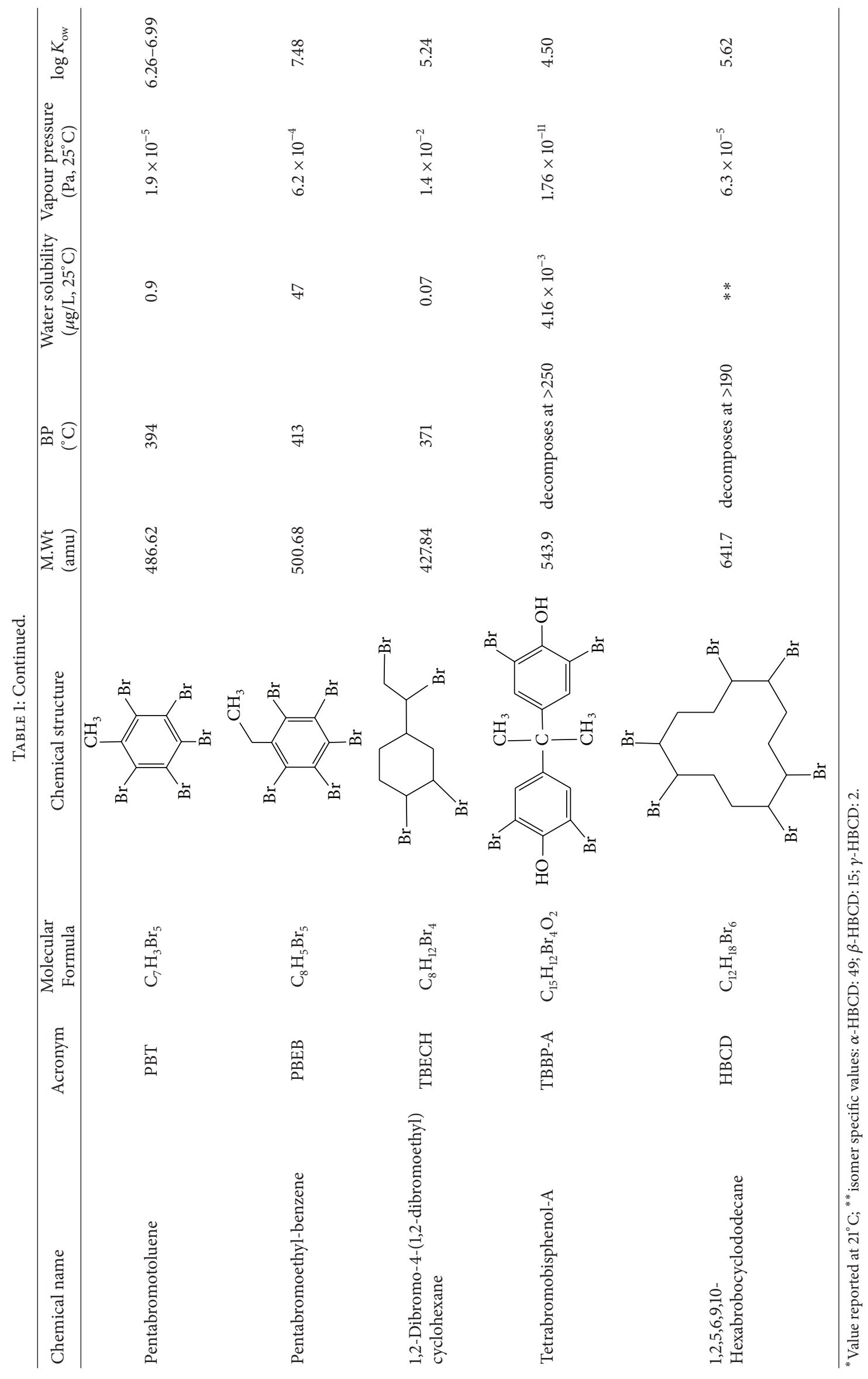




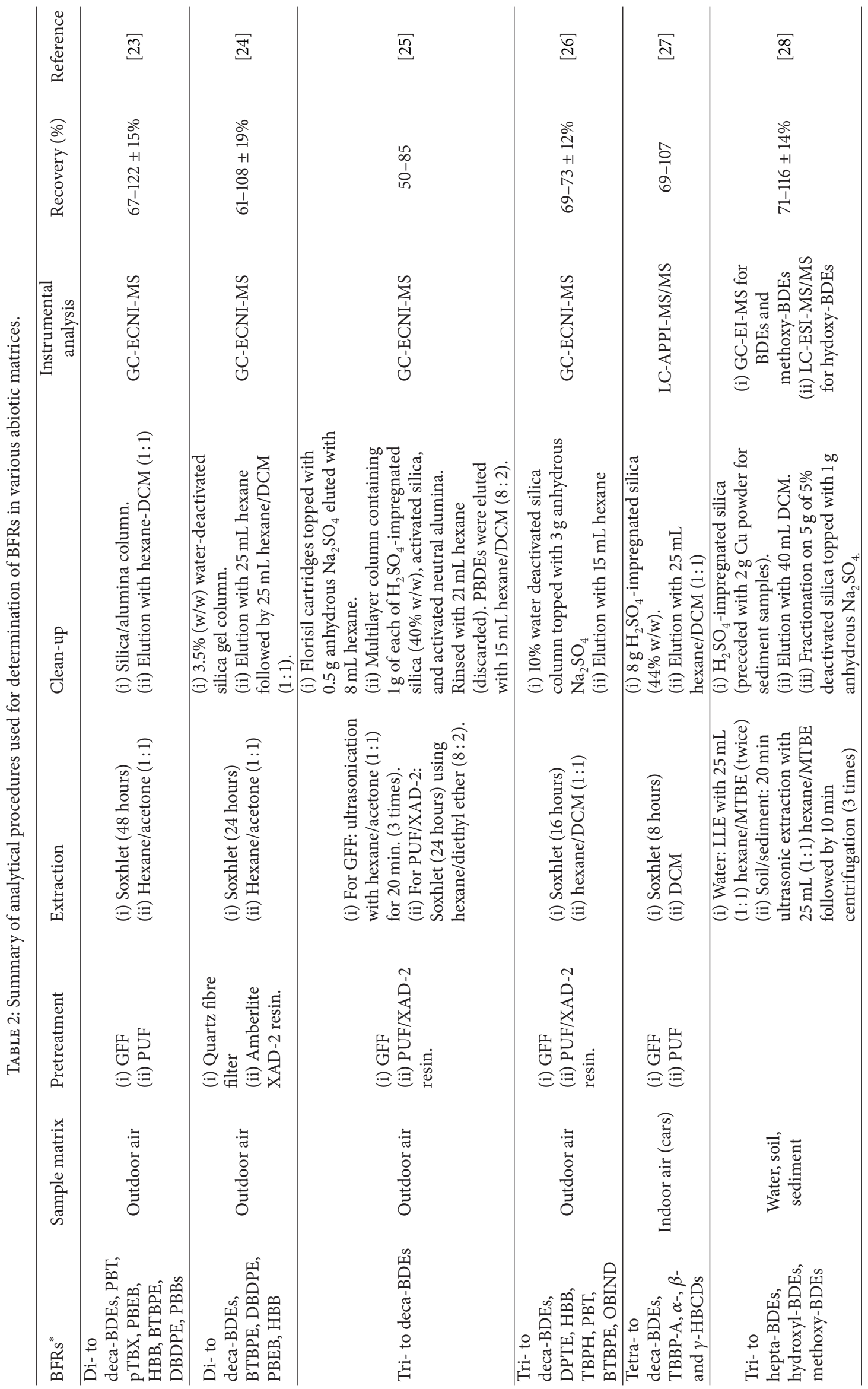




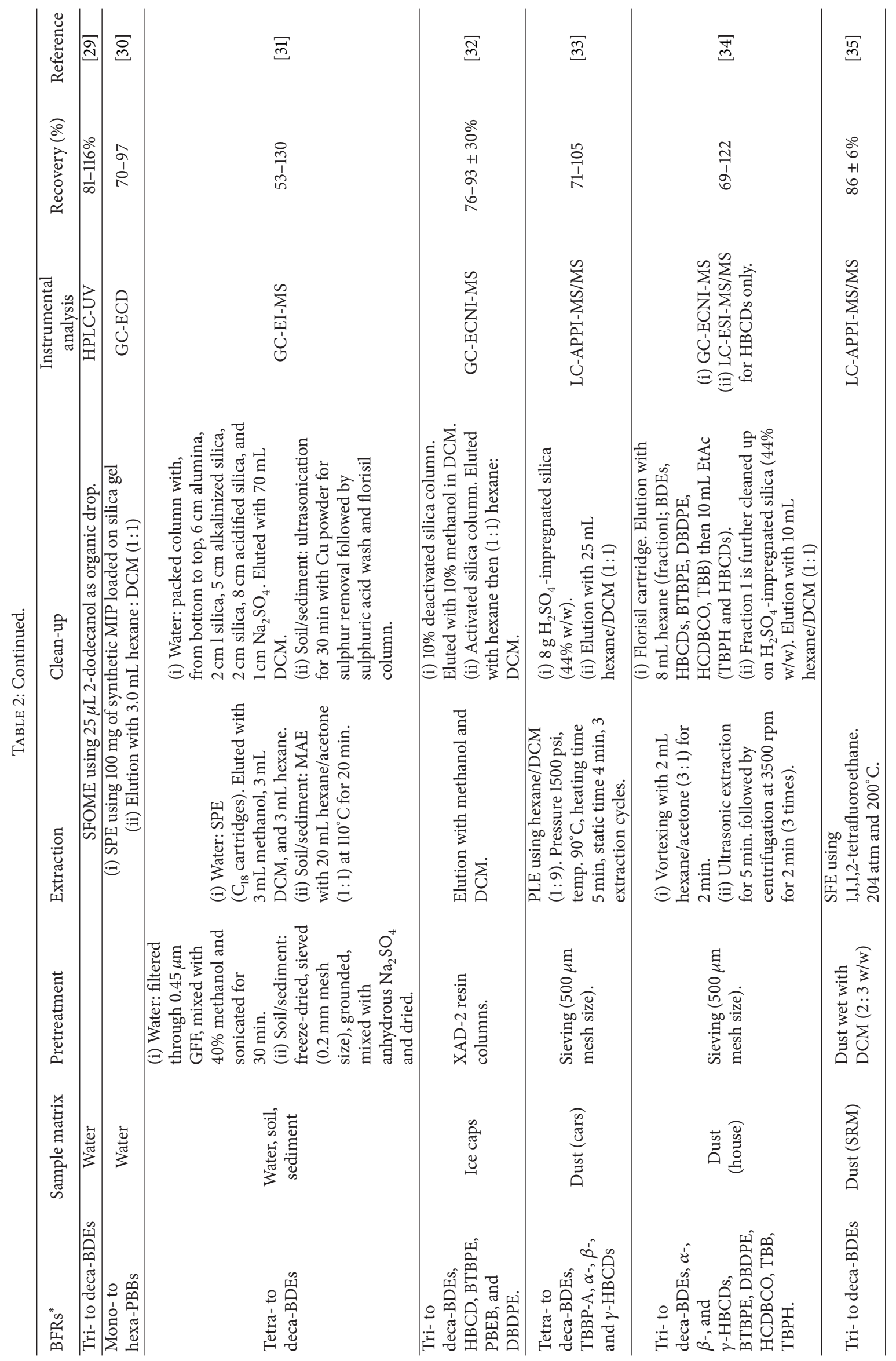




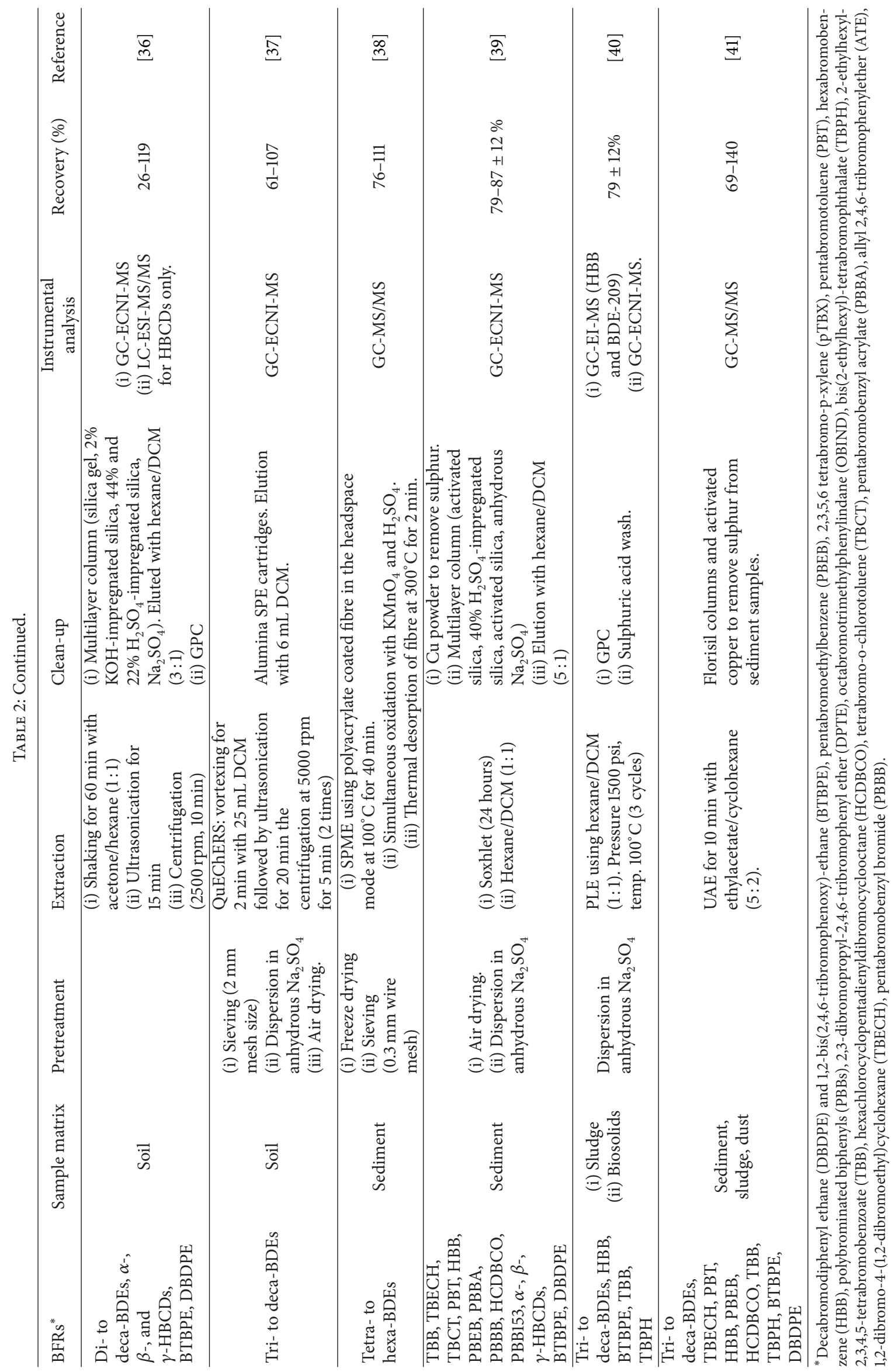


International Scholarly Research Notices

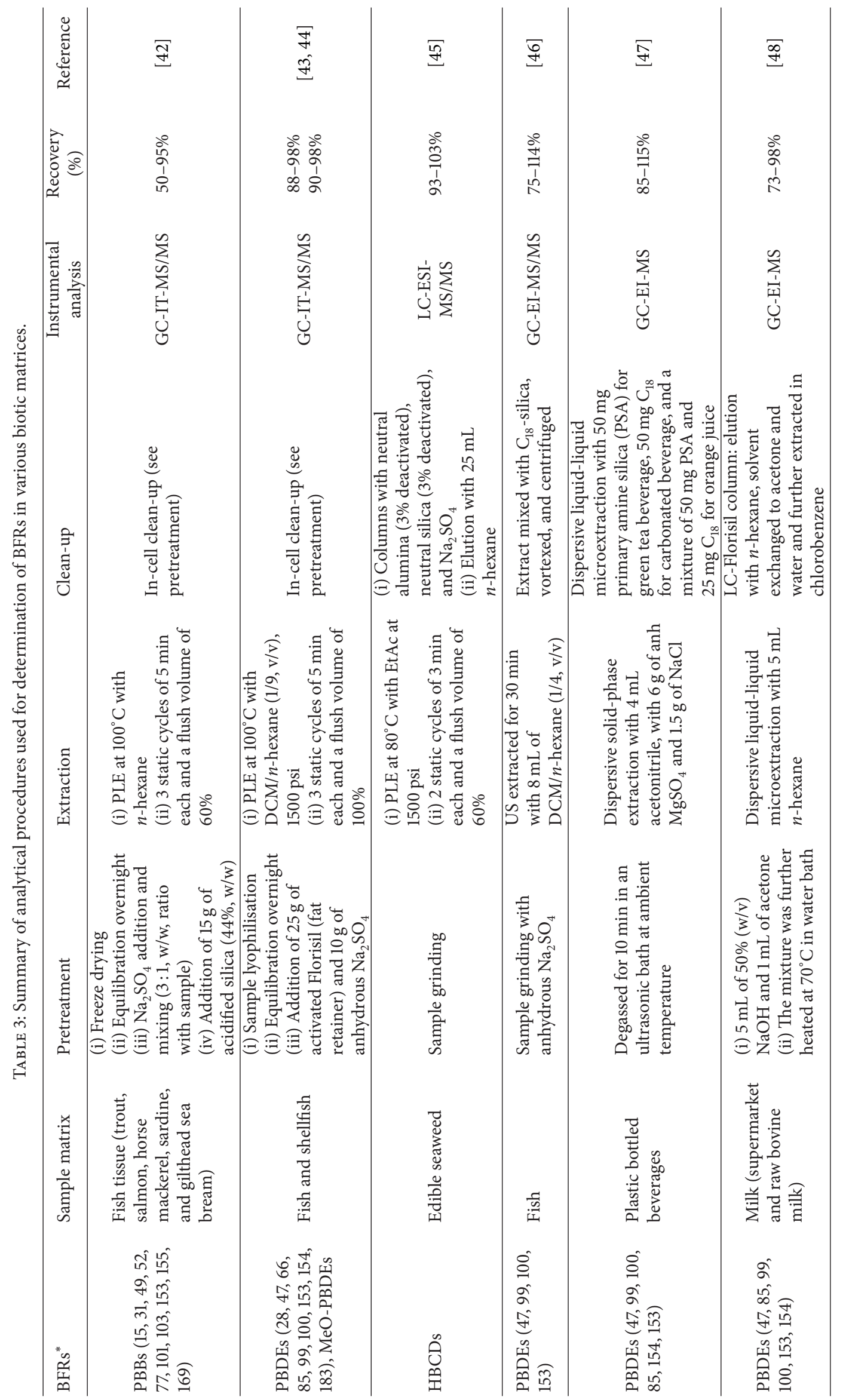




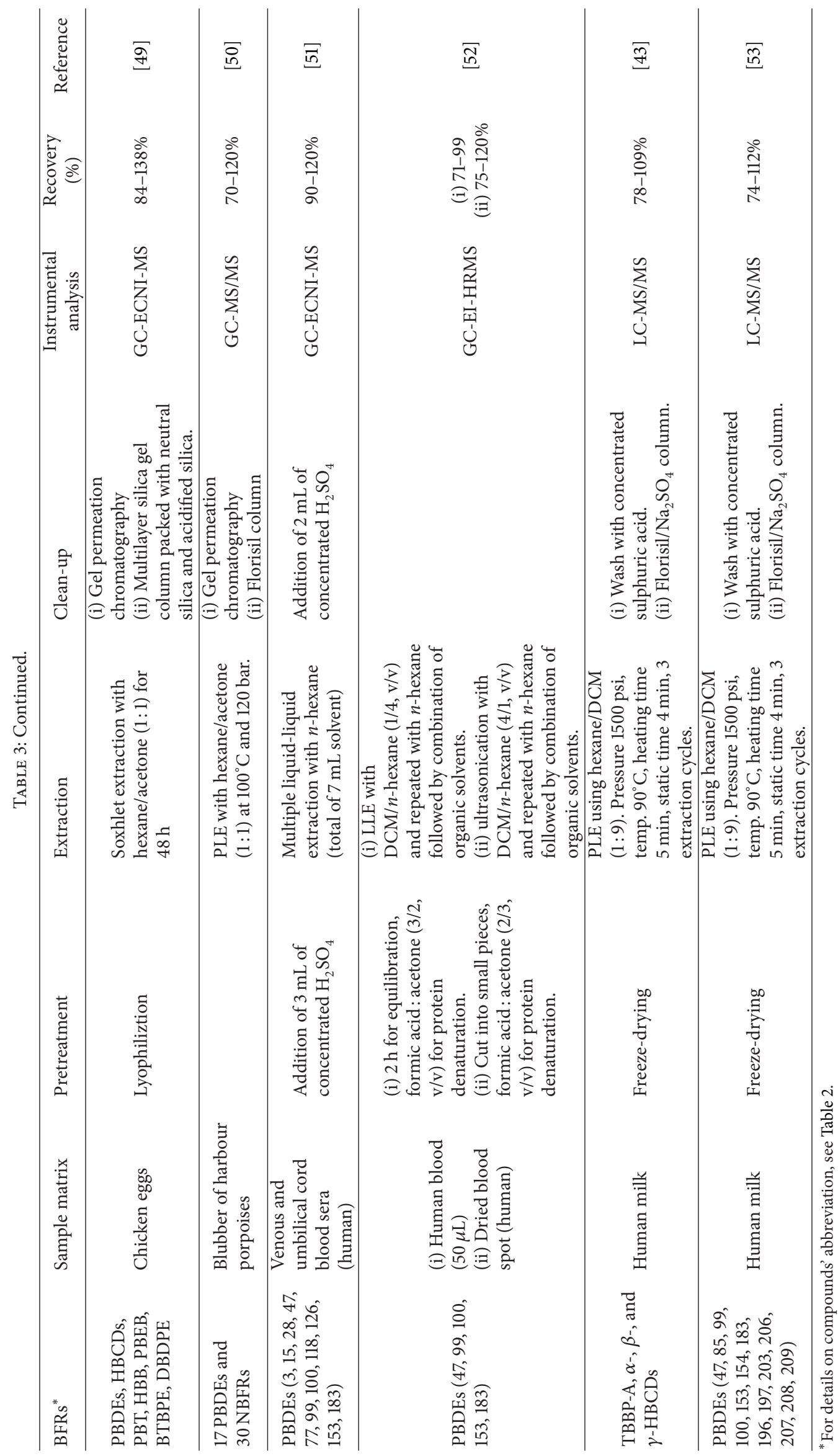




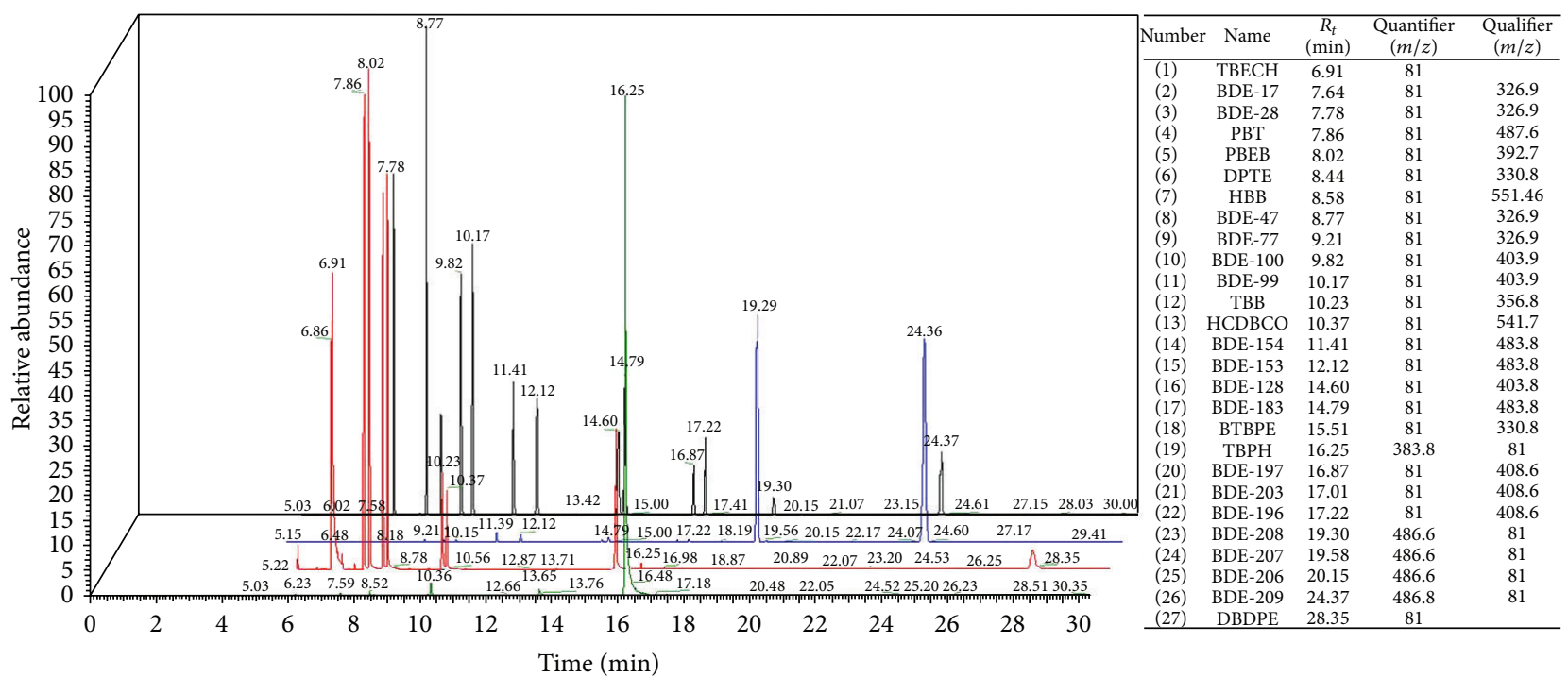

Figure 1: 3D-stacked GC-ECNI/MS chromatograms of $0.5 \mathrm{ng} / \mu \mathrm{L}$ standard mixtures of various PBDEs and NBFRs.

for analysis of NBFRs composed of 5\% phenyl; 95\% dimethyl polysiloxane (e.g., DB5-MS from J\&W), in most cases with a thin film thickness $(0.10 .25 \mu \mathrm{m})$ [62]. This combination is particularly favoured due to short on-column residence time and reduced retention which is beneficial for high $\mathrm{M}$.Wt compounds (e.g., DBDPE, BTBPE, and TBBPA-DBPE) or for NBFRs that are prone to on-column thermal decomposition or isomer interconversion [62]. However, single dimension GC cannot separate all PBDE congeners even with the most efficient stationary phase (22 coelutions were observed on a DB-XLB phase [61]). Therefore, Korytár et al. evaluated 6 column combinations for 2 dimensional GC $\times$ GC separation of PBDEs. Results revealed that a DB- $1 \times 007-65 \mathrm{HT}$ (Quadrex) combination was the most suitable combination because of (a) the highest number of PBDE congeners separated, (b) less decomposition of higher brominated congeners, and (c) most suitable maximum operating temperature [63].

Generally, short columns (10-15 m) are currently used for routine analysis of major PBDEs and NBFRs. while these columns provide the advantage of minimal thermal degradation and isomerisation of high M.Wt BFRs (e.g., BDE-209 and DBDPE), coelution of TBB with BDE 99 has been described using this type of column [64]. Longer GC columns $(25-60 \mathrm{~m})$ were applied to achieve better analyte separation, especially when NBFRs and PBDEs were simultaneously analysed or for confirmation purposes $[65,66]$. Vetter and Rosenfelder reported on the retention data of 122 environmentally-relevant polybrominated compounds including PBDEs, HBCDs, and NBFRs using a $30 \mathrm{~m}$ HP-5MS column. Potential coelutions were reported and discussed including that of Allyl 2,4,6-tribromophenyl ether (ATE) with BDE-10 [67]. Phenolic BFRs usually require derivatisation prior to injection onto the relatively nonpolar columns used for BFR analysis. Phenolic NBFRs including TBBP-A, 2,4dibromophenol (2,4-DBP), 2,4,6-tribromophenol (TBP), and pentabromophenol (PBP) were successfully separated on a $25 \mathrm{~m}$ CPSil-8 column following derivatisation with acetic anhydride [68]. A $30 \mathrm{~m} \mathrm{HP-1} \mathrm{column} \mathrm{was} \mathrm{used} \mathrm{for} \mathrm{the} \mathrm{analysis}$ of 2,4-DBP, 2,4,6-TBP, and PBP following their silylation with bis-(trimethylsilyl)-trifluoroacetamide (BSTFA) [69]. A method for the simultaneous determination of underivatised phenolic BFRs as well as their byproducts, formulation intermediates, and decomposition products was reported using a $60 \mathrm{~m}$ CPSil-8-CB column [70]. GC/MS methods could not be used for diastereomer- or enantiomer-specific analysis of HBCDs due to isomeric interconversion at temperatures $>160^{\circ} \mathrm{C}[71]$.

3.1.3. Mass Spectrometric Detection. Both high resolution (HR) and low resolution (LR) single quadrupole mass spectrometers have been widely applied for detection and quantification of PBDEs and their methoxylated derivatives [72, 73]. The LR/MS instruments could be operated in either electron ionization (EI) or negative chemical ionization (NCI) mode. In EI/MS, the major ions reported for PBDE analysis were $[\mathrm{M}]^{+}$and $[\mathrm{M}-2 \mathrm{Br}]^{+}[74]$. While this can provide more selectivity for identification and structural confirmation of target PBDEs, LR-EI/MS is not commonly used for analysis of higher PBDEs (more than $6 \mathrm{Br}$ atoms) due to reduced sensitivity. For instance, GC-EI/MS operated in SIM mode was successfully applied for analysis of PBDEs in human hair samples with LOQ as low as $0.3-0.6 \mathrm{ng} / \mathrm{g}$ for tri- to hepta-BDEs and $3 \mathrm{ng} / \mathrm{g}$ for BDE-209 [75]. Therefore, NCI, also known as ECNI (electron capture negative ionisation), has been more widely used for determination of high M.Wt. PBDEs. Most PBDEs (except for BDE-209) do not produce abundant stable molecular or fragment ions in the ECNI source; hence, only bromide ions $(\mathrm{m} / z 79$ and 81$)$ can be monitored. This reduced selectivity of the ECNI source precludes the use of ${ }^{13} \mathrm{C}$-labelled PBDEs as internal standards, except for BDE209 which produces a stable $\left[\mathrm{C}_{6} \mathrm{Br}_{5} \mathrm{O}\right]^{-}$fragment $(\mathrm{m} / z$ 486.7) allowing for the use of ${ }^{13} \mathrm{C}-\mathrm{BDE}-209$ as internal standard [58]. Nevertheless, the high sensitivity of GC-ECNI/MS rendered it the most commonly used method for analysis of major PBDEs in addition to other NBFRs (Figure 1) in various biotic and abiotic matrices $[18,62]$. Furthermore, selectivity 
of GC-ECNI/MS can be improved via optimisation of the electron energy, emission current, source temperature, and system pressure to increase the relative abundances of larger molecular fragments $[\mathrm{M}-x \mathrm{H}-y \mathrm{Br}]^{-}$which enables the monitoring of each $\mathrm{PBDE}$ homologue group rather than the non-specific bromide ions [76]. Monitoring high mass fragments of PBDEs under optimised ion source conditions was successfully applied for analysis of PBDEs in snow and human serum samples at concentration levels $<0.01 \mathrm{pg} / \mathrm{mL}$ [77].

While bromide ions $(m / z 79,81)$ were usually monitored for most NBFRs in GC-ECNI/MS [78], other ions were occasionally reported for specific compounds. For example, TBPH was analyzed via monitoring molecular fragments at $m / z 463,461$ [79] and $m / z 463,515$ [64]. In addition, the coelution of TBB with BDE-99 rendered it necessary to use fragment ions $(\mathrm{m} / z 357,471)$ for its monitoring to improve method selectivity [64]. Although not available to most laboratories, gas chromatography-high resolution mass spectrometry in EI mode (GC-HR-EI-MS) was applied successfully for detection and quantification of a wide range of NBFRs including ATE, TBCO, TBB, BATE, PBEB, DPTE, HBB, HCDBCO, DP, TBECH, BTBPE, BEHTBP, OBIND, and DBDPE [80].

Recently, further advanced MS techniques were applied for multiresidue analysis of BFRs. GC- time of flight (TOF)MS was applied for analysis of PBDEs, along with PCBs, in soil samples with LODs of $0.1-0.6 \mathrm{ng} / \mathrm{g}$ dry weight [81]. A method based on GC-MS/MS was described for analysis of PBDEs, along with PCBs and organochlorine pesticides (OCs), in human breast tissues with LODs as low as $0.5 \mathrm{ng} / \mathrm{g}$ (50 ng/g for BDE-209). Analyses were performed in both EIselected reaction monitoring (SRM) mode and NCI-selected ion recording (SIR) mode where the acquisition of - at least2 SRM transitions (in EI) or ions (in NCI) per analyte allowed positive findings to be confirmed by accomplishment of ion ratios between the quantification and the confirmation transitions or ions [82]. Another GC coupled to ion trap tandem mass spectrometry (GC-IT-MS/MS) method was successfully applied for monitoring a wide range of PBDEs and NBFRs, together with Dechlorane plus, in the blubber of harbor porpoises. The method achieved low LODs $(<1 \mathrm{ng} / \mathrm{g}$ lipid weight) and high precision (RSD $<15 \%)$ for all target analytes [50]. Another interesting approach was the use of comprehensive two-dimensional gas chromatography coupled to atmospheric pressure chemical ionizationhigh resolution time-of-flight-mass spectrometry $(\mathrm{GC} \times \mathrm{GC}$ APCI-TOF/HRMS) for analysis of a wide range of BFRs and plasticizers with absolute LODs in the range $0.5-25 \mathrm{pg}$. The method took the advantage of using a soft ionization technique that provides mainly molecular ions, in addition to the accuracy of HRMS for identification of a wide range of compounds. The application of direct probing provided a very easy and inexpensive method for the identification of flame retardants without any sample preparation. This technique seems extremely useful for the screening of solid materials such as electrical devices, electronics, and other waste [83].
3.2. LC/MS Analysis. The inherent problems encountered with GC/MS analysis due to the high temperatures applied resulted in several difficulties in the analysis of some BFRs. Particularly, HBCDs where isomeric interconversion takes place at temperatures $>160^{\circ} \mathrm{C}$ rendering isomeric separation impossible on GC columns [19]. Another problem encountered with GC/MS analysis of BFRs is thermal decomposition of high molecular weight compounds (e.g., BDE209, DBDPE, and TBBPA-DBPE) [84]. While the use of ${ }^{13} \mathrm{C}-\mathrm{BDE}-209$ as surrogate standard can-to some extentaccount for the inevitable on-column degradation of BDE209 during GC-NCI/MS analysis, similar approaches could not be achieved for DBDPE and TBBPA-DBPE due to the lack of stable molecular fragments other than $m / z=81$ in the NCI source $[84,85]$. Furthermore, the increased interest in relatively polar compounds such as TBBP-A and hydroxylated PBDE metabolites meant that a derivatisation step is required prior to their GC/MS analysis which may result in significant analyte loss and reduced recoveries [16, 86]. Therefore, LC/MS analysis emerged as an alternative technique to avoid the problems encountered during the analysis of thermolabile and relatively polar compounds by GC/MS.

3.2.1. $H B C D$. $\mathrm{HBCD}$ is produced via bromination of cyclododeca-1,5,9-triene (CDT) resulting in the creation of six stereo centers at positions $1,2,5,6,9$, and 10 of the formed product. This can give rise to a total of 16 possible optical isomers, 6 pairs of enantiomers, and 4 meso forms. To date, only 3 diastereomers-named $\alpha-, \beta$-, and $\gamma$-HBCD-were detected in the technical formulations and environmental samples with minor contributions (up to $0.5 \%$ ) of two meso forms named $\delta$ - and $\varepsilon$-HBCDs [87].

\section{(1) Diastereomer-Specific Analysis}

Stationary Phase. Tomy et al. [88] reported on baseline separation of $\mathrm{HBCD}$ diastereomers on a $\mathrm{C}_{18}$-reversed phase column. While a $5 \mu \mathrm{m}$ particle size column (Vydac 218MS, Mandel Scientific, Guelph, ON, Canada) packing is sufficient for baseline separation of $\alpha-, \beta$-, and $\gamma$-HBCDs, better resolution with sharper peaks (Figure 2) was reported using $3 \mu \mathrm{m}$ particle size (Pursuit XRS3, Agilent, CA, USA) [89]. Shorter retention times $(<8 \mathrm{~min})$ with narrower peaks could be achieved with $\mathrm{C}_{18}$ UPLC columns with $1.8 \mu \mathrm{m}$ particles (Acquity HSS T3, Waters, MA, USA) [90]. Moreover, separation of $\alpha-, \beta-, \gamma^{-}, \delta_{-}$, and $\varepsilon$-HBCDs was achieved on a $1.7 \mu \mathrm{m}$ UPLC column (Acquity UPLC BEH, Waters, MA, USA) [91].

Mobile Phase. Several mobile phase gradients using different combinations of methanol/acetonitrile/water were reported for separation of HBCD diastereomers [19]. While the MS response of an ESI source for $200 \mathrm{pg} / \mu \mathrm{L}$ solution of HBCDs in methanol was reported to be slightly higher than that in acetonitrile [92], addition of acetonitrile to the mobile phase (up to 20\%) resulted in improved resolution of the 3 main HBCD diastereomers (mainly between $\beta$ - and $\gamma$-isomers) which is recommended when the 2 minor meso forms ( $\delta$ - and $\varepsilon$-HBCD) are to be monitored [91]. Different mobile phase 


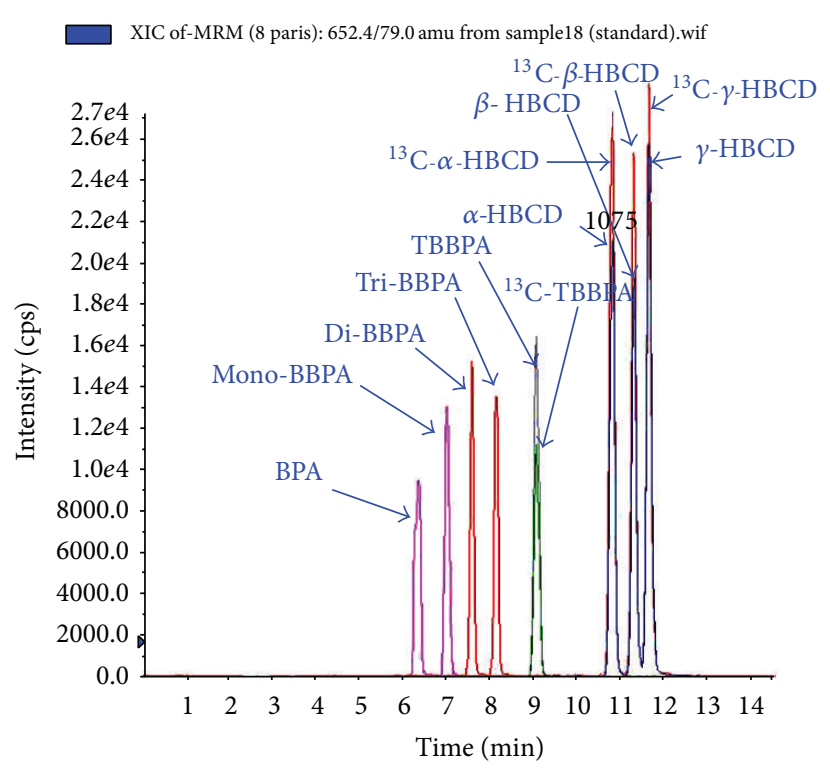

FIGURE 2: LC-ESI-MS/MS chromatogram of $0.5 \mathrm{ng} / \mu \mathrm{L}$ standard mixtures of BPA, mono-BBPA, di-BBPA, tri-BBPA, TBBPA, and $\alpha-, \beta-$, and $\gamma$-HBCDs.

modifiers (e.g., ammonium acetate [93], ammonium chloride [94], and acetic acid [95]) were reported to produce sharper peaks and improve separation efficiency of HBCDs.

\section{(2) Enantiomer-Specific Separation}

Stationary Phase. Only one chiral stationary phase was reported in literature for efficient separation of $\mathrm{HBCD}$ enantiomers. Baseline resolution of the 6 enantiomers from an $\alpha$-, $\beta$-, and $\gamma$-HBCD mixture was achieved on $\beta$-permethylated cyclodextrin bonded (NUCLEODEX, Macherey-Nagel, GmbH, Düren, Germany) chiral LC column $(4 \times 200 \mathrm{~mm}, 5 \mu \mathrm{m})$ [96]. It was observed that $(-)-\alpha$ - and $(-)-\beta$-HBCD eluted before their corresponding $(+)-\alpha$ - and $(+)-\beta$-HBCD enantiomers (Figure 3 ). These were followed by the $\gamma$-enantiomers with $(+)-\gamma$ - eluting ahead of $(-)-\gamma$ HBCD [97]. While the chiral column is sufficient for baseline separation of HBCD enantiomers, Yu et al. [98] connected a $\mathrm{C}_{18}$ achiral column to the $\beta$-permethylated chiral stationary phase in order to separate the HBCD diastereomers prior to enantiomeric resolution. This provided clear distinction between the respective enantiomers of each HBCD diastereomer in the resulting chromatograms (Figure 3).

Mobile Phase. A combination of methanol/acetonitrile/water in the mobile phase is mandatory for separation of $\mathrm{HBCD}$ enantiomers [99]. Interestingly, Marvin et al. [100] found that both mobile phase composition and column bleed could affect the MS response for different HBCD enantiomers. Dodder et al. [101] observed that the MS response changed between the elution of two enantiomers due to the extracted matrix component. In order to avoid such effects on the estimated enantiomeric fractions (EF), Marvin et al. [85] introduced a mathematical formula for calculation of corrected EF values (see (1)). This correction is based on the use of isotopic-labelled standards (e.g., $\mathrm{d}_{18}$-HBCDs) since the labelled enantiomeric analogs behave identically to their native counterparts in the MS source [100]:

$$
\mathrm{EF}_{\text {corrected }}=\frac{\left[\left(A^{+} / A_{\text {labeled }}^{+}\right) \times\left(\operatorname{pg} A_{\text {labeled }}^{+}\right)\right]}{\left[\left(A^{+} / A_{\text {labeled }}^{+}\right) \times\left(\operatorname{pg} A_{\text {labeled }}^{+}\right)\right]+\left[\left(A^{-} / A_{\text {labeled }}^{-}\right) \times\left(\operatorname{pg} A_{\text {labeled }}^{-}\right)\right]},
$$

where $A^{+}$is the peak area of the $(+)$enantiomer, $A_{\text {labelled }}^{+}$is the peak area of the labelled ( + ) enantiomer, $\operatorname{pg} A_{\text {labelled }}^{+}$is the mass of labeled isomer added in picograms, $A^{-}$is the peak area of the $(-)$ enantiomer, $A_{\text {labelled }}^{-}$is the peak area of the labelled ( - ) enantiomer, and $\mathrm{pg} A_{\text {labelled }}^{-}$is the mass of labelled isomer added in picograms.

(3) Mass Spectrometric Detection. Several mass spectrometric techniques were reported for detection of HBCDs. Morris et al. applied both single quadrupole MS and ion trap MS for detection of HBCDs in sediment and biota samples [102]. Although HBCD molecular ion $\left([\mathrm{M}-\mathrm{H}]^{-} ; m / z=640.7\right)$ was monitored in both techniques, differences in instrumental response to the three studied HBCD diastereomers were observed. $\alpha$-HBCD recorded the highest response using the single quadrupole MS, while the ion trap MS was most sensitive to $\gamma$-HBCD. Nevertheless, the use of tandem mass (MS/MS) detection in triple quadrupole (QpQ) mass spectrometers provided high sensitivity and very low LODs ( $\leq 1 \mathrm{pg}$ on column) for all HBCD diastereomers using 


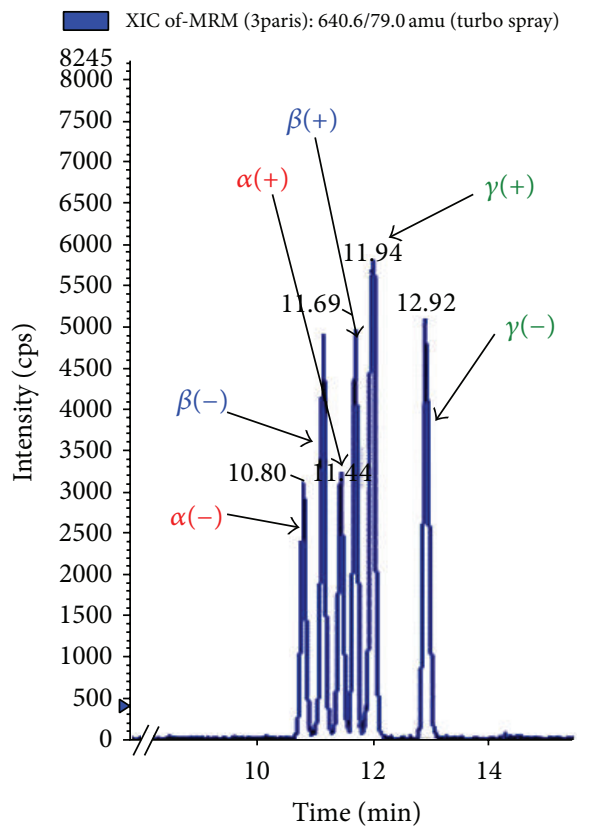

(a)

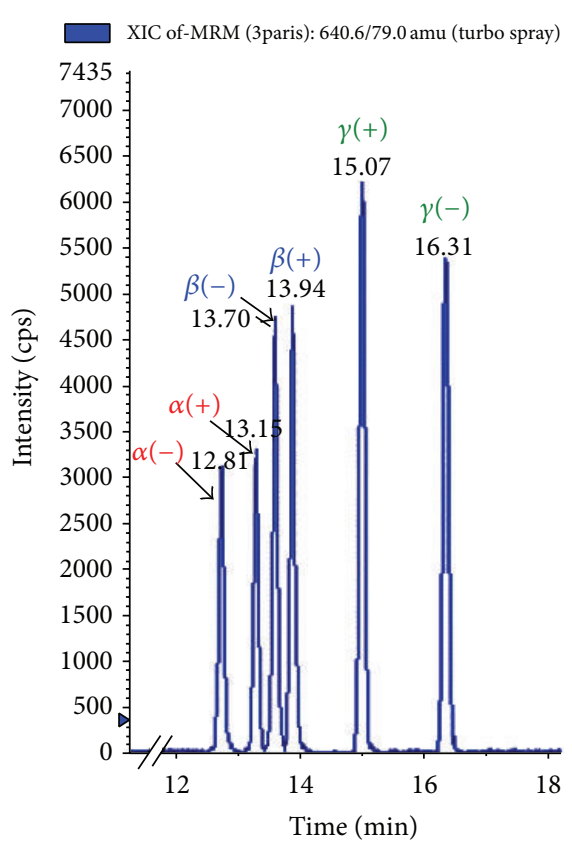

(b)

FIGURE 3: LC-MS/MS chromatograms showing chiral separation of $50 \mathrm{pg} / \mu \mathrm{L} \alpha-, \beta-, \gamma$-HBCDs using (a) Nucleodex $\beta$-PM chiral LC column and (b) Pursuit XRS3 C18 column followed by Nucleodex $\beta$-PM chiral LC column.

the ion transition $[\mathrm{M}-\mathrm{H}]^{-} \rightarrow \mathrm{Br}^{-}[58]$. While electrospray ionisation (ESI) source in negative ion mode is the most commonly used interface for HBCD analysis, both atmospheric pressure photoionisation (APPI) [103] and atmospheric pressure chemical ionisation (APCI) [104] sources proved as useful for HBCD detection. Matrix-related ion suppression issues and differences in the response factors to $\alpha-, \beta$, and $\gamma$-HBCD diastereomers were identified as the major challenges encountered with MS/MS analysis of HBCDs using ESI. These drawbacks can be overcome by the use of ${ }^{13} \mathrm{C}$ - or $\mathrm{d}_{18}$-labelled HBCDs (monitored at $\mathrm{m} / z 652.4 \rightarrow$ 79 and $657.6 \rightarrow 79$, resp.) as surrogate and/or recovery standards. The mass labelled standards behave similarly to native $\mathrm{HBCD}$ in the ion source and can compensate for matrix-related effects. Furthermore, both instrumental response and matrix-related ion suppression varied for $\alpha$-, $\beta$ , and $\gamma$-HBCDs indicating that a labelled internal standard is required for each isomer to obtain accurate results (Figure 2) [88].

To enhance the sensitivity of LC-ESI-MS/MS analysis of $\mathrm{HBCD}$ enantiomers, the formation of $\mathrm{Cl}^{-}$and $\mathrm{CH}_{3} \mathrm{COO}^{-}$ adducts via addition of $\mathrm{NH}_{4} \mathrm{Cl}$ and $\mathrm{CH}_{3} \mathrm{COONH}_{4}$ to the mobile phase was investigated [105]. While both approaches presented a comparable behaviour for the analysis of food samples, the $\mathrm{Cl}^{-}$method $(m / z 676.6 \rightarrow 640.6)$ showed higher sensitivity and the LODs $(0.2-0.4 \mathrm{pg}$ on column) and LOQs (0.7-1.4 pg on column) were up to 14 times lower than those obtained applying the $\mathrm{CH}_{3} \mathrm{COO}^{-}$method $(m / z 700.6 \rightarrow$ 640.6). Another interesting approach involves the use of Anion attachment atmospheric pressure photoionization (AA-APPI), with 1,4-dibromobutane in toluene as a bromide source for analysis of HBCDs $(m / z 722.6 \rightarrow 79)$ in sediment samples. This method offered increased sensitivity and lower limits of detection than APPI. Furthermore, minimal matrix effects were found with AAAPPI in sediment extracts providing a major advantage over ESI-based methods [106].

3.2.2. TBBP-A. Avoiding the derivatisation step of phenolic $\mathrm{OH}$ groups required prior to GC/MS analysis of TBBPA was not the only advantage gained by using LC/MS for determination of this BFR. Another advantage was the possible use of ${ }^{13} \mathrm{C}$-labelled TBBP-A as an internal standard which greatly improves the quality of analytical data obtained via compensation for matrix-related effects that can affect analyte ion intensity [16].

(1) Stationary Phase. Several studies have reported the use of $\mathrm{C}_{18} \mathrm{RP}$ columns with various dimensions and particle sizes for analysis of TBBP-A [16]. In general, TBBP-A is rarely measured alone and is usually included in multiresidue analytical methodology for analysis of various BFRs [107]. Guerra et al. applied a Symmetry $C_{18}$ column $(2.1 \times 150 \mathrm{~mm}$, $5 \mu \mathrm{m})$ preceded by a $C_{18}$ guard column $(2.1 \times 10 \mathrm{~mm})$ supplied by Waters (Milford, MA, USA) for baseline separation of TBBPA and related compounds bisphenol A (BPA), monobromobisphenol A (MonoBBPA), dibromobisphenol A (DiBBPA), and tribromobisphenol A (TriBBPA) in sewage sludge and sediment samples [108]. Application of UPLC columns (Acquity HSS T3, $100 \times 2.1 \mathrm{~mm}, 1.8 \mu \mathrm{m}$, Waters, MA, USA) resulted in a shorter retention time (6.5 minutes) than HPLC columns [90].

(2) Mobile Phase. Chu et al. reported that, by using methanol as mobile phase, the LC-ESI-MS/MS response factor for 
TBBP-A was $\sim$ one third greater than when acetonitrile was used due to a more stable detector baseline [109]. Similar results were recently reported by Lankova et al. using the Turbo V ion source for UPLC-MS/MS analysis of TBBP-A in fish samples [90]. Therefore, multiresidue analytical methods for determination of TBBP-A with other BFRs applied only methanol/water mobile phase gradients (Figure 2) [90, 93, $108,110]$.

(3) Mass Spectrometric Detection. Unlike HBCDs, Tollbäck et al. found that ESI source in negative ion mode is the most suitable interface for TBBP-A analysis with LC-MS providing 30-40 times lower LODs than those obtained by APCI [111]. Therefore, LC-ESI-MS/MS in negative ion mode was widely reported for determination of TBBP-A concentrations in various environmental matrices via monitoring the mass transitions corresponding to $[\mathrm{M}-\mathrm{H}]^{-} \rightarrow \mathrm{Br}^{-}$ $\left(m / z 542.6 \rightarrow 79\right.$ and $552.6 \rightarrow 79$ for native and ${ }^{13} \mathrm{C}$ TBBP-A, resp.) [16].

Although early studies were focused on the use of triple quadrupole mass spectrometers, the high selectivity of iontrap MS was applied for the determination of TBBPA in sediment and sewage sludge scanning the range from $\mathrm{m} / z$ 145-543 after LC separation [112]. Guerra et al. described a method based on liquid chromatography/quadrupole linear ion trap mass spectrometry (LC-QqLIT-MS) for separation and quantification of TBBPA and related compounds bisphenol A (BPA), monobromobisphenol A (Mono-BBPA), dibromobisphenol A (Di-BBPA), and tribromobisphenol A (Tri-BBPA) together with $\alpha-, \beta$, and $\gamma$-HBCD diastereomers in sewage sludge and sediment samples [108]. The reported method displayed excellent LODs in selective reaction monitoring (SRM) mode (0.1-1.8 pg), but even better results were obtained in enhanced product ion (EPI) mode (0.01-0.5 pg). Interestingly, desorption atmospheric pressure photoionization-mass spectrometry (DAPPI-MS) in negative ion mode was applied successfully for analysis of TBBP-A in circuit board and orange peel samples using anisole as spraying solvent. This method displayed the advantages of minimal sample treatment and low LOD (0.3 ng/g) [113]. Recently, a different approach was adopted for analysis of TBBP-A in plasma and serum samples using LC-ESI(+)MS/MS. The method is based on derivatisation of TBBP-A in the extracts using dansyl chloride reagent. The dansylated derivatives are then monitored at $m / z 505.9 \rightarrow 171.1$ and $512.9 \rightarrow 171.1$ for native and ${ }^{13} \mathrm{C}$-TBBP-A with method LOQ as low as $0.03 \mathrm{ng} / \mathrm{g}$ [114].

3.2.3. PBDEs and NBFRs. Fewer studies have reported on the analysis of PBDEs and NBFRs using LC/MS techniques. This may be attributed to the presence of well-established, sensitive, and efficient protocols for analysis of these hydrophobic compounds using GC/MS techniques. However, LC/MS analysis can provide a major advantage for analysis of heavy molecular weight BFRs (e.g., BDE-209 and DBDPE) which may undergo thermal degradation and/or extensive fragmentation during the course of GC/MS analysis [58]. LC/MS methods in ESI mode may have limited use for PBDEs due to poor ionization in this source [115]. Abdallah et al. reported an isotope dilution method using ${ }^{13} \mathrm{C}$-labelled internal standards for quantification of 14 major tetra- to deca-PBDEs using LC-NI-APPI/MS/MS. The 14 PBDEs were baseline separated on $\mathrm{C}_{18}$-RP column (Pursuit XRS3, $250 \times$ $4.6 \mathrm{~mm}, 3 \mu \mathrm{m}$, Agilent, CA, USA) using mobile phase gradient of methanol/toluene and water. The method applied the soft photoionisation technique to obtain stable pseudomolecular ions $[\mathrm{M}-\mathrm{Br}+\mathrm{O}]^{-}$and $[\mathrm{M}-2 \mathrm{Br}+\mathrm{O}]^{-}$in $\mathrm{Q} 1$ which enabled the use of isotopically labelled internal standard for quantification [116]. The method was then successfully applied for analysis of PBDEs in dust [116], air [117], and human milk samples [118]. Zhou et al. [103] developed a sensitive and high throughput LC-NI-APPI-MS/MS method for the analysis of 36 brominated flame retardants including PBDEs, HBCDs, TBBP-A, and several NBFRs in fish samples. The method used an Ultra-II $\mathrm{C}_{18}$ column $(100 \times 2.1 \mathrm{~mm}, 2.2 \mu \mathrm{m}$, RESTEK, PA, USA) operated at $25^{\circ} \mathrm{C}$ for separation of target compounds with a methanol/water mobile phase gradient at a flow rate of $400 \mu \mathrm{L} / \mathrm{min}$. In comparison with acetone, toluene provided around $10 \%$ higher ion intensity for less hydrophobic compounds. Three categories of precursor ions were observed in the APPI source: (1) displacement products, for example, $[\mathrm{M}-\mathrm{Br}+\mathrm{O}]^{-}$and $\left[\mathrm{M}-\mathrm{HBr}-\mathrm{Br}+\mathrm{O}_{2}\right]^{-}$; (2) elimination products, for example, $[\mathrm{M}-\mathrm{H}]^{-}$and (3) association product, for example $\left[\mathrm{M}+\mathrm{O}_{2}\right]^{-}$. The dominant precursor ion used for quantification of the studied BFRs was $[\mathrm{M}-\mathrm{Br}+\mathrm{O}]^{-}[103]$. In another study, APCI source was investigated by the same authors for determination of 38 BFRs in wastewater samples. For MS/MS detection, relatively high collision energy was required to produce abundant $\mathrm{Br}^{-}$product ions, and the authors suggested increasing the collision gas pressure may generate more of these ions. The method was simple, sensitive, and applicable to compounds with a wide range of physicochemical properties [119]. Mascolo et al. used a $\mathrm{C}_{18}-\mathrm{BEH}$ column $(150 \times 2.1 \mathrm{~mm}$, $1.7 \mu \mathrm{m}$ ) for separation of 11 tetra- to deca-PBDEs. The column was kept at $40^{\circ} \mathrm{C}$ while separation was achieved using a methanol/water gradient. Method LODs as low as 3-198 pg/g and 4-380 pg/g were reported for APCI and APPI (toluene as dopant) sources, respectively. Depending on the PBDE congener, the APCI source was 2-8 times more sensitive than APPI [120].

Letcher and Chu reported the application of LC-NIAPPI-MS/MS for quantification of TBBPA-S-DBPE, TBBPA$\mathrm{AE}$, and TBBPA-DBPE in herring gull eggs. Target analytes were separated on a ZOBRAX SB-C ${ }_{18}$ column $(2.1 \times 30 \mathrm{~mm}$, $3.5 \mu \mathrm{m})$.The method depends on the use of acetone as both the organic solvent in the mobile phase and the doping agent for the APPI source. The studied compounds were quantified via monitoring $m / z 997.4 \rightarrow 79,655.8 \rightarrow 79$, and $975.5 \rightarrow 79$ for TBBPA-S-DBPE, TBBPA-AE, and TBBPA-DBPE, respectively, corresponding to $\left[\mathrm{M}+\mathrm{O}_{2}\right]^{-} \rightarrow$ $\mathrm{Br}^{-}$transition [121]. More recently, TBBPA-AE and TBBPADBPE were analysed by APCI-MS/MS after separation on a $\mathrm{C}_{18}$ column $(150 \times 2.1 \mathrm{~mm}, 5 \mu \mathrm{m})$ using methanol/water mobile phase. The studied compounds were monitored at $m / z 582.9 \rightarrow 526.5$ and $742.7 \rightarrow 526.5$ for TBBPAAE and TBBPA-DBPE, respectively. Method LOD ranged from $10-30 \mathrm{pg} / \mathrm{g}$ in various environmental samples [122]. 
Finally, Arsenault et al. reported an LC-ESI-MS method for analysis of TBECH isomers. TBECH is a novel BFR which has 4 thermolabile diastereomers that can interconvert at temperatures $\geq 125^{\circ} \mathrm{C}$. Incomplete separation of the 4 isomers was performed on a UPLC BEH $\mathrm{C}_{18}$ column $(2.1 \times$ $100 \mathrm{~mm}, 1.7 \mu \mathrm{m}$ ) with a methanol/acetonitrile/water gradient. Analytes were detected via monitoring $\mathrm{Br}^{-}$ions in SIM mode due to the lack of molecular ion formation in ESI source [123].

3.2.4. BFR Metabolites. The mounting scientific interest in BFRs in the past few years has resulted in an increasing number of studies on their fate and behaviour in the environment and humans. This lead to the development of analytical methodologies to monitor BFR metabolites and transformation products together with the parent compounds. Since most of the produced metabolites are more polar than the parent BFRs, LC-MS provides a useful, rapid, and sensitive technique for their analyses.

(1) HBCD Metabolites and Degradation Products. Abdallah et al. identified 4 isomers of pentabromocyclododecene (PBCD) and two isomers of tetrabromocyclododecadienes (TBCD) as transformation products of HBCDs in indoor dust. These transformation products were separated on a $\mathrm{C}_{18^{-}}$ $\mathrm{RP}$ column $(150 \times 2.1 \mathrm{~mm}, 3 \mu \mathrm{m})$ using a methanol/water gradient. PBCDs were monitored at 560.6 $\rightarrow 79$ while TBCDs were monitored at $480.4 \rightarrow 79$ using an ESI source in negative ion mode. Identification of these transformation products led the authors to hypothesize sequential debromination as a pathway of HBCD transformation [71]. Further studies by the authors using the same analytical method lead to identification of various TBCDs and PBCDs in fish [124] and human milk [110]. HBCD monohydroxylated metabolites were identified by Zegers et al. following in vitro incubation with liver microsomal enzymes of harbour porpoises [125]. The hydroxyl metabolites were separated on a $\mathrm{C}_{18}$-RP column $(150 \times 2.1 \mathrm{~mm}, 3.5 \mu \mathrm{m})$ and monitored at $m / z 656 \rightarrow 79$. Following exposure of female Wistar rats to technical HBCD mixture in feed, Brandsma et al. managed to identify a range of monohydroxyl metabolites of HBCDs, PBCDs, and TBCDs in addition to dihydroxylated PBCD [126]. Tissue extracts were separated into 17 fractions using $\mu$ Porasil NP-HPLC column $(10 \mu \mathrm{m}, 7.8 \times 300 \mathrm{~mm})$ prior to analysis by liquid chromatograph with a quadrupole ion trap mass spectrometer (LCQ-MS). The LCQ-MS system featured a Zorbax eclipse XDB- ${ }_{18}$ column $(150 \times 2.1 \mathrm{~mm}, 3.5 \mu \mathrm{m})$ preceded by a Zorbax $\mathrm{XDB}-\mathrm{C}_{8}$ guard column, while a mixture of acetonitrile $/ 0.01 \mathrm{mM}$ ammonium chloride was used as mobile phase. The MS was equipped with an ESI source operated in negative ion mode, while all the target analytes were monitored at $m / z$ values equivalent to their $[\mathrm{M}+\mathrm{Cl}]^{-}$adduct which provided higher sensitivity than the quasimolecular ion species [126]. Hydroxylated metabolites of individual HBCD enantiomers were identified following in vitro incubation with rat liver microsomes [127]. Separation of target analytes was achieved on a combination of Zorbax XDB- $\mathrm{C}_{18}$ column $(1.8 \mu \mathrm{m}, 150 \times 4.6 \mathrm{~mm})$ and a chiral NUCLEODEX $\beta$-PM $(5 \mu \mathrm{m}, 200 \times 4.6 \mathrm{~mm})$ analytical column maintained at $15^{\circ} \mathrm{C}$ using a mixture of methanol/acetonitrile $/ 10 \mathrm{mM}$ ammonium acetate as mobile phase. The mass transitions of $656.7 \rightarrow 79$ and $672.6 \rightarrow 79$ were established to monitor mono- and dihydroxy-HBCD metabolites. More recently, Abdallah et al. optimised a method for simultaneous analysis of HBCDs, PBCDs, TBCDs and their hydroxylated metabolites following in vitro incubation experiments with rat and trout hepatic subcellular (S9) fractions. The method used a combination of a Pursuit XRS3 $\mathrm{C}_{18}$ column $(150 \times$ $2.1 \mathrm{~mm}, 3 \mu \mathrm{m})$ and a NUCLEODEX $\beta$-PM $(200 \times 4.6 \mathrm{~mm}$, $5 \mu \mathrm{m}$ ) chiral column [128]. All target analytes were monitored at MRM corresponding to their respective $[\mathrm{M}-\mathrm{H}]^{-} \rightarrow \mathrm{Br}^{-}$ mass transitions.

(2) PBDE Metabolites. Introduction of one or more hydroxyl groups to $\mathrm{PBDEs}$ can result in the formation of more toxic metabolites due to close structural similarity to the thyroid hormones [129]. Hydroxyl PBDE metabolites are nonvolatile, relatively polar compounds which require derivatisation prior to GC/MS analysis. GC-MS methods for analysis of $\mathrm{OH}-\mathrm{PBDE}$ metabolites must include a derivatization step with diazomethane, which needs to be handled with care due to its explosive characteristics. Furthermore, the efficiency of the derivatization step varies from sample to sample, since the reaction may give a yield less than $100 \%$. Finally, additional sample-preparation or clean-up steps could introduce errors and lengthen analysis time [86]. Therefore, LC-MS is the method of choice for rapid, fast, and sensitive analysis of these compounds [107]. It was reported that ionisation of PBDEs and their metabolites by the ESI source is poor [130]. Therefore, focus has shifted to the application of APCI and APPI sources for their ionisation. Hydroxylated and methoxylated metabolites of tetra-PBDEs were analysed in marine biota using LC-APCI-MS/MS in negative ion mode. Chromatographic separation was performed on a $\mathrm{C}_{18}$ analytical column $(150 \times 4.6 \mathrm{~mm}, 3 \mu \mathrm{m})$ with acetonitrile/water mobile phase. Multiple reaction monitoring (MRM) was performed using the precursor $[\mathrm{M}-\mathrm{H}]^{-}$ion for hydroxylated analogs and the $[\mathrm{M}-\mathrm{Br}+\mathrm{O}]^{-}$ion for tetra-PBDEs and their methoxylated analogs. Method LOQs ranged from 0.11 to $43 \mathrm{ng} / \mathrm{g} \mathrm{lw}$ [131]. Nine OH-PBDEs, ranging from tri- to hexabrominated were separated and quantified using a similar LC-APCIMS/MS method. Notably, a significant decrease in ionization was observed in 6-OH-substituted PBDE metabolites with orthosubstituted bromine, relative to the other hydroxylated metabolites. This was attributed to the formation of dioxins as a result of high-temperature conditions in the APCI source, which prevented ionization by hydrogen abstraction. The MS/MS experiments also provided evidence of the neutral losses of $\mathrm{HBr}$ and $\mathrm{Br} 2$, indicating the possible use of neutral loss scanning and selected reaction monitoring (SRM) for screening of brominated metabolites [86]. Liquid chromatography-electrospray tandem triple quadrupolelinear ion trap mass spectrometer (LC-ESI-QqLIT-MS-MS) in negative mode method was developed for the determination of eleven OH-tri- to OH-hexa-PBDEs [132]. The optimal conditions for proper chromatographic separation of the studied OH-PBDE congeners were the following: Purospher STAR RP-18 endcapped column $(125 \times 2 \mathrm{~mm}, 5 \mu \mathrm{m})$ working 
at $\mathrm{pH}=10$, using $\mathrm{ACN}$ and water/methanol $3: 2$ as mobile phase. Selected reaction monitoring (SRM) was used in order to increase sensitivity using transitions corresponding to $[\mathrm{M}-\mathrm{H}]^{-} \rightarrow \mathrm{Br}^{-}$for all target metabolites. Instrumental LOQs ranged between $0.6-2 \mathrm{pg}$ on column [132]. APPI was also reported for simultaneous analysis of PBDEs and their hydroxylated metabolites [115]. Following separation on a UPLC Hypersil Gold $\mathrm{C}_{18}$ column $(100 \times 2.1 \mathrm{~mm}, 1.9 \mu \mathrm{m})$ using methanol/water/acetone mobile phase gradient. The optimised method was based on APPI ionization (acetone as dopant) coupled to high-resolution mass spectrometry operating in the full scan mode at a resolution of 60,000 (LTQ-Orbitrap XL mass spectrometer). This provided excellent sensitivity and specificity, allowing the discrimination of signals which could not be resolved on a triple quadrupole used as a reference. The full-scan high-resolution acquisition mode allowed monitoring of both parent PBDEs and their metabolites, including hydroxylated PBDEs, with detection limits ranging from 0.1 to $4.5 \mathrm{pg}$ injected oncolumn [115]. LC-ESI(+)-MS/MS was reported for analysis of $14 \mathrm{OH}-\mathrm{PBDE}$ in serum following derivatisation with dansyl chloride. Chromatographic separation was achieved on a Luna PFP- 2 column $(2 \times 100 \mathrm{~mm}, 3 \mu \mathrm{m})$ with a mobile phase of water/acetonitrile (both containing $0.1 \%$ formic acid). Derivatization and analysis by LC-ESI(+)-MS/MS was reported to produce an intense molecular ion $[\mathrm{M}+\mathrm{H}]^{+}$ peak and thus a much higher ionization efficiency and yield. Under MS/MS conditions, the dansylated precursor ions also produced an intense fragment ion at $m / z 171$ corresponding to the 5-(dimethylamino)-naphthalene moiety. LODs ranged from 0.01 to $014 \mathrm{ng} / \mathrm{g}$ for the 14 target OH-PBDEs [114]. An interesting approach involving the use of a comprehensive two-dimensional system coupling UPLC and ion mobility-mass spectrometry (IM-MS) was reported for analysis of 23 mono- to octa-OH-PBDEs. The first-dimensional reversed-phase UPLC was performed on a BEH $\mathrm{C}_{18}(150 \times$ $2.1 \mathrm{~mm}, 1.7 \mu \mathrm{m})$ chromatographic column using acetonitrile/water gradient elution program with a flow rate ramp. It enabled excellent chromatographic separation for both between-class and within-class OH-PBDEs based on their differences in hydrophobicity. Following the preionization resolution in the first dimension, the second-dimensional IM-MS employed a hybrid electrospray quadrupole ion mobility time-of-flight mass spectrometer and added an extra postionization separation for between-class OH-PBDE congeners on account of their relative mobility disparity during a very short period of $8.8 \mathrm{~ms}$. The two-dimensional separation plane also contributed to the removal of background interference ions and the enhanced confidence in the characterization of OH-PBDEs of interest [133].

\section{Current Challenges and Future Perspectives}

Screening recent literature on methodologies reported for analysis of different BFRs in various environmental matrices has revealed a few challenges highlighted by several authors. While the methods for extraction and clean-up of different BFRs vary slightly according to physicochemical parameters of target analytes, very little is known about these important parameters for NBFRs [14]. Therefore, more validated studies on important physicochemical parameters of NBFRs (e.g., Henry's law constant, water solubility, $\log K_{\text {ow }}$, and air/water partition coefficients) are required to allow for the development of multiresidue analytical methods and to improve the current understanding of the environmental behaviour of these contaminants. This will also be reflected in the sampling strategies adopted to collect these NBFRs from various environmental matrices.

The continuously escalating global interest in monitoring different classes of environmental contaminants implies the need for efficient, rapid, and high throughput analytical methods. The availability of integrated sample-preparation systems (e.g., automated sample extraction with online cleanup and volume reduction systems) makes them an ideal choice to reduce sample-processing time and to achieve the high-throughput analysis required to process large numbers of samples in environmental monitoring programs with a good precision. While current application of such integrated systems in environmental analysis is limited by their high prices that add to the overall cost of analysis, commercial competition and continuous development are likely to expand their applications in the near future.

Considering the rapid advances of MS-based instrumental techniques, development of analytical methods for smaller amounts of sample is desirable. The concept of small sample volume becomes more attractive with the increasing scientific interest in dried blood spot (DBS) analysis for monitoring of various contaminant groups in human blood [134]. Small sample mass is likely to reduce the matrixrelated interferences which entail time-consuming clean-up steps. Yet, such approach necessitates high sensitivities and low method LODs which can only be achieved via rigorous optimization of instrumental parameters.

The large number of legacy and novel BFRs in the market together with the limited budget for their analysis in environmental samples necessitates further development of multiresidue analytical methodologies for simultaneous identification/quantification of various classes of BFRs together with other environmental contaminants in the same sample within a reasonable run time via application of advanced hyphenated analytical techniques, for example, GC $\times$ GCTOF/MS, UPLC-MS/MS, UPLC-HRMS.

Finally, the inclusion of new contaminants (e.g., NBFRs) in existing monitoring protocols is recommended. However, this highlights the need for commercially-available reference standards (labelled and unlabelled) for these compounds, together with the certification of appropriate biotic and abiotic reference materials which are necessary to validate the analytical methods developed and produce accurate results.

\section{Conflict of Interests}

The author declares that there is no conflict of interests regarding the publication of this paper. 


\section{References}

[1] M. A.-E. Abdallah, Investigating the sources and magnitude of human exposure to halogenated organic pollutants using advanced methods for environmental analysis [Ph.D. thesis], University of Birmingham, Birmingham, UK, 2010.

[2] European Flame Retardants Association, What are FRs? Flame Retardant Market Statistics, European Flame Retardants Association, 2007.

[3] BSEF, Bromine Science and Environmental Forum, 2013, http:// www.bsef.com/.

[4] R. A. Diaz-Bone and T. R. van de Wiele, "Biovolatilization of metal(loid)s by intestinal microorganisms in the simulator of the human intestinal microbial ecosystem," Environmental Science \& Technology, vol. 43, no. 14, pp. 5249-5256, 2009.

[5] J. Cheng, J. Gu, J. Ma, X. Chen, M. Zhang, and W. Wang, "Neurobehavioural effects, redox responses and tissue distribution in rat offspring developmental exposure to BDE-99," Chemosphere, vol. 75, no. 7, pp. 963-968, 2009.

[6] P. O. Darnerud, "Brominated flame retardants as possible endocrine disrupters," International Journal of Andrology, vol. 31, no. 2, pp. 152-160, 2008.

[7] J. D. Meeker, P. I. Johnson, D. Camann, and R. Hauser, "Polybrominated diphenyl ether (PBDE) concentrations in house dust are related to hormone levels in men," Science of the Total Environment, vol. 407, no. 10, pp. 3425-3429, 2009.

[8] K. Akutsu, S. Takatori, S. Nozawa et al., "Polybrominated diphenyl ethers in human serum and sperm quality," Bulletin of Environmental Contamination and Toxicology, vol. 80, no. 4, pp. 345-350, 2008.

[9] M. E. Turyk, V. W. Persky, P. Imm, L. Knobeloch, R. Chatterton Jr., and H. A. Anderson, "Hormone disruption by PBDEs in adult male sport fish consumers," Environmental Health Perspectives, vol. 116, no. 12, pp. 1635-1641, 2008.

[10] K. M. Main, H. Kiviranta, H. E. Virtanen et al., "Flame retardants in placenta and breast milk and cryptorchildism in newborn boys," Environmental Health Perspectives, vol. 115, no. 10, pp. 1519-1526, 2007.

[11] H.-R. Chao, S.-L. Wang, W.-J. Lee, Y.-F. Wang, and O. Päpke, "Levels of polybrominated diphenyl ethers (PBDEs) in breast milk from central Taiwan and their relation to infant birth outcome and maternal menstruation effects," Environment International, vol. 33, no. 2, pp. 239-245, 2007.

[12] Stockholm Convention on Persistent Organic Pollutants, New POPs: Decisions\&Recommendations, Directions SC-4/14, SC4/18 and SC-6/13, http://chm.pops.int/Implementation/NewPOPs/DecisionsRecommendations/tabid/671/Default.aspx.

[13] S. Harrad and M. Diamond, "New Directions: exposure to polybrominated diphenyl ethers (PBDEs) and polychlorinated biphenyls (PCBs): current and future scenarios," Atmospheric Environment, vol. 40, no. 6, pp. 1187-1188, 2006.

[14] A. Covaci, S. Harrad, M. A.-E. Abdallah et al., "Novel brominated flame retardants: a review of their analysis, environmental fate and behaviour," Environment International, vol. 37, no. 2, pp. 532-556, 2011.

[15] M. Harju, E. Heimstad, D. Herzke, T. Sandanger, S. Posner, and F. Wania, Current state of knowledge and monitoring requirements - Emerging "new" brominated flame retardants in flame retarded products and the environment (TA-2462/2008), http://www.miljodirektoratet.no/old/klif/publikasjoner/2462/ ta2462.pdf.
[16] A. Covaci, S. Voorspoels, M. A.-E. Abdallah, T. Geens, S. Harrad, and R. J. Law, "Analytical and environmental aspects of the flame retardant tetrabromobisphenol-A and its derivatives," Journal of Chromatography A, vol. 1216, no. 3, pp. 346-363, 2009.

[17] J. Wang, Y. J. Ma, S. J. Chen, M. Tian, X. J. Luo, and B. X. Mai, "Brominated flame retardants in house dust from e-waste recycling and urban areas in south China: implications on human exposure," Environment International, vol. 36, no. 6, pp. 535-541, 010.

[18] M. Frederiksen, K. Vorkamp, M. Thomsen, and L. E. Knudsen, "Human internal and external exposure to PBDEs-a review of levels and sources," International Journal of Hygiene and Environmental Health, vol. 212, no. 2, pp. 109-134, 2009.

[19] NICNAS 2007, "National Industrial Chemicals Notification and Assessment Scheme alert no. 6 Perfluorooctanoic acid (PFOA) \& Perfluorocarboxylic acid (PFCA)," 2007, http://www.nicnas .gov.au/communications/publications/information-sheets/ existing-chemical-info-sheets/pfc-derivatives-and-chemicalson-which-they-are-based-alert-factsheet.

[20] C. H. Marvin, G. T. Tomy, J. M. Armitage et al., "Hexabromocyclododecane: current understanding of chemistry, environmental fate and toxicology and implications for global management," Environmental Science \& Technology, vol. 45, no. 20, pp. 8613-8623, 2011.

[21] S. Harrad, C. A. de Wit, M. A.-E. Abdallah et al., "Indoor contamination with hexabromocyclododecanes, polybrominated diphenyl ethers, and perfluoroalkyl compounds: an important exposure pathway for people?" Environmental Science and Technology, vol. 44, no. 9, pp. 3221-3231, 2010.

[22] A. C. Dirtu, A. Covaci, and M. Abdallah, "Advances in the sample preparation of brominated flame retardants and other brominated compounds," Trends in Analytical Chemistry, vol. 43, pp. 189-203, 2013.

[23] M. Tian, S.-J. Chen, J. Wang, X.-B. Zheng, X.-J. Luo, and B.$\mathrm{X}$. Mai, "Brominated flame retardants in the atmosphere of Ewaste and rural sites in Southern China: seasonal variation, temperature dependence, and gas-particle partitioning," Environmental Science \& Technology, vol. 45, no. 20, pp. 8819-8825, 2011.

[24] A. Salamova and R. A. Hites, "Discontinued and alternative brominated flame retardants in the atmosphere and precipitation from the great lakes basin," Environmental Science \& Technology, vol. 45, no. 20, pp. 8698-8706, 2011.

[25] K. Tlili, P. Labadie, F. Alliot, C. Bourges, and M. Chevreuil, "Polybrominated diphenyl ether dynamics in ambient air and atmospheric bulk/wet deposition in downtown Paris (France)," Water, Air, \& Soil Pollution, vol. 223, no. 4, pp. 1543-1553, 2012.

[26] A. Möller, Z. Xie, M. Cai, R. Sturm, and R. Ebinghaus, "Brominated flame retardants and dechlorane plus in the marine atmosphere from Southeast Asia toward Antarctica," Environmental Science \& Technology, vol. 46, no. 6, pp. 31413148, 2012.

[27] T. R. van de Wiele, A. G. Oomen, J. Wragg et al., "Comparison of five in vitro digestion models to in vivo experimental results: lead bioaccessibility in the human gastrointestinal tract," Journal of Environmental Science and Health A: Toxic/Hazardous Substances and Environmental Engineering, vol. 42, no. 9, pp. 1203-1211, 2007.

[28] J. Sun, J. Liu, Q. Liu, G. Qu, T. Ruan, and G. Jiang, "Sample preparation method for the speciation of polybrominated diphenyl ethers and their methoxylated and hydroxylated 
analogues in diverse environmental matrices," Talanta, vol. 88, pp. 669-676, 2012.

[29] H. Liu, M. Zhang, X. Wang et al., "Extraction and determination of polybrominated diphenyl ethers in water and urine samples using solidified floating organic drop microextraction along with high performance liquid chromatography," Microchimica Acta, vol. 176, no. 3-4, pp. 303-309, 2012.

[30] H. Zhu, L. Ma, G. Fang et al., "Preparation of a molecularly imprinted polymer using TMB as a dummy template and its application as SPE sorbent for determination of six PBBs in water and fish samples," Analytical Methods, vol. 3, no. 2, pp. 393-399, 2011.

[31] J. Wang, Z. Lin, K. Lin et al., "Polybrominated diphenyl ethers in water, sediment, soil, and biological samples from different industrial areas in Zhejiang, China," Journal of Hazardous Materials, vol. 197, pp. 211-219, 2011.

[32] T. Meyer, D. C. G. Muir, C. Teixeira, X. Wang, T. Young, and F. Wania, "Deposition of brominated flame retardants to the Devon Ice Cap, Nunavut, Canada," Environmental Science \& Technology, vol. 46, no. 2, pp. 826-833, 2012.

[33] S. Harrad and M. A.-E. Abdallah, "Brominated flame retardants in dust from UK cars-within-vehicle spatial variability, evidence for degradation and exposure implications," Chemosphere, vol. 82, no. 9, pp. 1240-1245, 2011.

[34] N. van den Eede, A. C. Dirtu, N. Ali, H. Neels, and A. Covaci, "Multi-residue method for the determination of brominated and organophosphate flame retardants in indoor dust," Talanta, vol. 89, pp. 292-300, 2012.

[35] F. C. Calvosa and A. F. Lagalante, "Supercritical fluid extraction of polybrominated diphenyl ethers (PBDEs) from house dust with supercritical 1,1,1,2-tetrafluoroethane (R134a)," Talanta, vol. 80, no. 3, pp. 1116-1120, 2010.

[36] M. Ilyas, A. Sudaryanto, I. E. Setiawan et al., "Characterization of polychlorinated biphenyls and brominated flame retardants in surface soils from Surabaya, Indonesia," Chemosphere, vol. 83, no. 6, pp. 783-791, 2011.

[37] N. A. Andrade, L. L. Mcconnell, A. Torrents, and M. Ramirez, "Persistence of polybrominated diphenyl ethers in agricultural soils after biosolids applications," Journal of Agricultural and Food Chemistry, vol. 58, no. 5, pp. 3077-3084, 2010.

[38] R. Montes, I. Rodríguez, and R. Cela, "Solid-phase microextraction with simultaneous oxidative sample treatment for the sensitive determination of tetra- to hexa-brominated diphenyl ethers in sediments," Journal of Chromatography A, vol. 1217, no. 1, pp. 14-21, 2010.

[39] R. Yang, H. Wei, J. Guo, and A. Li, "Emerging brominated flame retardants in the sediment of the Great Lakes," Environmental Science \& Technology, vol. 46, no. 6, pp. 3119-3126, 2012.

[40] E. F. Davis, S. L. Klosterhaus, and H. M. Stapleton, "Measurement of flame retardants and triclosan in municipal sewage sludge and biosolids," Environment International, vol. 40, no. 1, pp. 1-7, 2012.

[41] J. Cristale and S. Lacorte, "Development and validation of a multiresidue method for the analysis of polybrominated diphenyl ethers, new brominated and organophosphorus flame retardants in sediment, sludge and dust," Journal of Chromatography A, vol. 1305, pp. 267-275, 2013.

[42] J. Malavia, F. J. Santos, and M. T. Galceran, "Simultaneous pressurized liquid extraction and clean-up for the analysis of polybrominated biphenyls by gas chromatography-tandem mass spectrometry," Talanta, vol. 84, no. 4, pp. 1155-1162, 2011.
[43] M. A.-E. Abdallah and S. Harrad, "Tetrabromobisphenol-A, hexabromocyclododecane and its degradation products in UK human milk: relationship to external exposure," Environment International, vol. 37, no. 2, pp. 443-448, 2011.

[44] S. Losada, F. J. Santos, A. Covaci, and M. T. Galceran, "Gas chromatography-ion trap tandem mass spectrometry method for the analysis of methoxylated polybrominated diphenyl ethers in fish," Journal of Chromatography A, vol. 1217, no. 32, pp. 5253-5260, 2010.

[45] C. Han, X. Chen, W. Xie et al., "Determination of hexabromocyclododecane diastereoisomers in Sargassum fusiforme and comparison of the extraction efficiency of ultrasonication, microwave-assisted extraction, Soxhlet extraction and pressurised liquid extraction," Journal of Separation Science, vol. 33, no. 21, pp. 3319-3325, 2010.

[46] A. R. Fontana, A. Camargo, L. D. Martinez, and J. C. Altamirano, "Dispersive solid-phase extraction as a simplified cleanup technique for biological sample extracts. Determination of polybrominated diphenyl ethers by gas chromatographytandem mass spectrometry," Journal of Chromatography A, vol. 1218, no. 18, pp. 2490-2496, 2011.

[47] Y. Han, X. Jia, X. Liu, T. Duan, and H. Chen, "Dispersive solid-phase extraction combined with dispersive liquid-liquid microextraction for the determination of polybrominated diphenyl ethers in plastic bottled beverage by GC-MS," Journal of Separation Science, vol. 34, no. 9, pp. 1047-1054, 2011.

[48] X. Liu, A. Zhao, A. Zhang et al., "Dispersive liquid-liquid microextraction and gas chromatography-mass spectrometry determination of polychlorinated biphenyls and polybrominated diphenyl ethers in milk," Journal of Separation Science, vol. 34, no. 9, pp. 1084-1090, 2011.

[49] L.-M. L. Toms, M. E. Bartkow, R. Symons, O. Paepke, and J. F. Mueller, "Assessment of polybrominated diphenyl ethers (PBDEs) in samples collected from indoor environments in South East Queensland, Australia," Chemosphere, vol. 76, no. 2, pp. 173-178, 2009.

[50] R. J. Law, S. Losada, J. L. Barber et al., "Alternative flame retardants, Dechlorane Plus and BDEs in the blubber of harbour porpoises (Phocoena phocoena) stranded or bycaught in the UK during 2008," Environment International, vol. 60, pp. 81-88, 2013.

[51] J. O. Grimalt, M. Howsam, D. Carrizo, R. Otero, M. R. R. de Marchi, and E. Vizcaino, "Integrated analysis of halogenated organic pollutants in sub-millilitre volumes of venous and umbilical cord blood sera," Analytical and Bioanalytical Chemistry, vol. 396, no. 6, pp. 2265-2272, 2010.

[52] D. Lu, D. Wang, H. S. S. Ip, F. Barley, R. Ramage, and J. She, "Measurements of polybrominated diphenyl ethers and polychlorinated biphenyls in a single drop of blood," Journal of Chromatography B: Analytical Technologies in the Biomedical and Life Sciences, vol. 891-892, pp. 36-43, 2012.

[53] M. A. Abdallah and S. Harrad, "Polybrominated diphenyl ethers in UK human milk: implications for infant exposure and relationship to external exposure," Environment International, vol. 63, pp. 130-136, 2013.

[54] K. Hooper, J. She, M. Sharp et al., "Depuration of polybrominated diphenyl ethers (PBDEs) and polychlorinated biphenyls (PCBs) in breast milk from California first-time mothers (primiparae)," Environmental Health Perspectives, vol. 115, no. 9, pp. 1271-1275, 2007.

[55] C. M. Butt, D. Wang, and H. M. Stapleton, "Halogenated phenolic contaminants inhibit the in vitro activity of the 
thyroid-regulating deiodinases in human liver," Toxicological Sciences, vol. 124, no. 2, pp. 339-347, 2011.

[56] J. Jia, N. Frantz, C. Khoo, G. R. Gibson, R. A. Rastall, and A. L. McCartney, "Investigation of the faecal microbiota associated with canine chronic diarrhea," FEMS Microbiology Ecology, vol. 71, no. 2, pp. 304-312, 2010.

[57] J. Björklund, P. Tollbäck, C. Hiärne, E. Dyremark, and C. Östman, "Influence of the injection technique and the column system on gas chromatographic determination of polybrominated diphenyl ethers," Journal of Chromatography A, vol. 1041, no. 1-2, pp. 201-210, 2004.

[58] A. Covaci, S. Voorspoels, L. Ramos, H. Neels, and R. Blust, "Recent developments in the analysis of brominated flame retardants and brominated natural compounds," Journal of Chromatography A, vol. 1153, no. 1-2, pp. 145-171, 2007.

[59] P. Tollbäck, J. Björklund, and C. Östman, "Large-volume programmed-temperature vaporiser injection for fast gas chromatography with electron capture and mass spectrometric detection of polybrominated diphenyl ethers," Journal of Chromatography A, vol. 991, no. 2, pp. 241-253, 2003.

[60] E. M. Cooper, H. M. Stapleton, C. W. Matson, R. T. Di Giulio, and A. J. Schuler, "Ultraviolet treatment and biodegradation of dibenzothiophene: identification and toxicity of products," Environmental Toxicology and Chemistry, vol. 29, no. 11, pp. 2409-2416, 2010.

[61] D. Wang and H. M. Stapleton, "Analysis of thyroid hormones in serum by liquid chromatography-tandem mass spectrometry," Analytical and Bioanalytical Chemistry, vol. 397, no. 5, pp. 18311839, 2010.

[62] Y. Lai, B.-L. Adam, R. Podolsky, and J.-X. She, "A mixture model approach to the tests of concordance and discordance between two large-scale experiments with two-sample groups," Bioinformatics, vol. 23, no. 10, pp. 1243-1250, 2007.

[63] P. Korytár, A. Covaci, P. E. G. Leonards, J. de Boer, and U. A. T. Brinkman, "Comprehensive two-dimensional gas chromatography of polybrominated diphenyl ethers," Journal of Chromatography A, vol. 1100, no. 2, pp. 200-207, 2005.

[64] H. M. Stapleton, J. G. Allen, S. M. Kelly et al., "Alternate and new brominated flame retardants detected in U.S. house dust," Environmental Science \& Technology, vol. 42, no. 18, pp. 69106916, 2008.

[65] S. Harrad, C. Ibarra, M. A.-E. Abdallah, R. Boon, H. Neels, and A. Covaci, "Concentrations of brominated flame retardants in dust from United Kingdom cars, homes, and offices: causes of variability and implications for human exposure," Environment International, vol. 34, no. 8, pp. 1170-1175, 2008.

[66] T. Geens, N. Ali, L. Roosens, H. Neels, and A. Covaci, "Analytical characteristics of several new brominated flame retardants," Talanta, vol. 81, no. 4-5, pp. 1865-1869, 2010.

[67] W. Vetter and N. Rosenfelder, "Gas chromatography retention data of environmentally relevant polybrominated compounds," Analytical and Bioanalytical Chemistry, vol. 392, no. 3, pp. 489504, 2008.

[68] M. Polo, M. Llompart, C. Garcia-Jares, G. Gomez-Noya, M.-H. Bollain, and R. Cela, "Development of a solid-phase microextraction method for the analysis of phenolic flame retardants in water samples," Journal of Chromatography A, vol. 1124, no. 1-2, pp. 11-21, 2006.

[69] A. Smeds and P. Saukko, "Brominated flame retardants and phenolic endocrine disrupters in Finnish human adipose tissue," Chemosphere, vol. 53, no. 9, pp. 1123-1130, 2003.
[70] J. G. Allen, M. D. Mcclean, H. M. Stapleton, and T. F. Webster, "Linking PBDEs in house dust to consumer products using Xray fluorescence," Environmental Science and Technology, vol. 42, no. 11, pp. 4222-4228, 2008.

[71] M. A.-E. Abdallah, C. Ibarra, H. Neels, S. Harrad, and A. Covaci, "Comparative evaluation of liquid chromatography-mass spectrometry versus gas chromatography-mass spectrometry for the determination of hexabromocyclododecanes and their degradation products in indoor dust," Journal of Chromatography A, vol. 1190, no. 1-2, pp. 333-341, 2008.

[72] R. A. Hites, "Electron impact and electron capture negative ionization mass spectra of polybrominated diphenyl ethers and methoxylated polybrominated diphenyl ethers," Environmental Science \& Technology, vol. 42, no. 7, pp. 2243-2252, 2008.

[73] S. Król, B. Zabiegała, and J. Namieśnik, "PBDEs in environmental samples: sampling and analysis," Talanta, vol. 93, pp. 1-17, 2012.

[74] M. J. La Guardia, R. C. Hale, and E. Harvey, "Detailed polybrominated diphenyl ether (PBDE) congener composition of the widely used penta-, octa-, and deca-PBDE technical flameretardant mixtures," Environmental Science \& Technology, vol. 40, no. 20, pp. 6247-6254, 2006.

[75] J. L. Tadeo, C. Sánchez-Brunete, and E. Miguel, "Determination of polybrominated diphenyl ethers in human hair by gas chromatography-mass spectrometry," Talanta, vol. 78, no. 1, pp. 138-143, 2009.

[76] L. K. Ackerman, G. R. Wilson, and S. L. Simonich, "Quantitative analysis of 39 polybrominated diphenyl ethers by isotope dilution GC/low-resolution MS," Analytical Chemistry, vol. 77, no. 7, pp. 1979-1987, 2005.

[77] E. Vizcaino, L. Arellano, P. Fernandez, and J. O. Grimalt, "Analysis of whole congener mixtures of polybromodiphenyl ethers by gas chromatography-mass spectrometry in both environmental and biological samples at femtogram levels," Journal of Chromatography A, vol. 1216, no. 25, pp. 5045-5051, 2009.

[78] N. Ali, S. Harrad, D. Muenhor, H. Neels, and A. Covaci, "Analytical characteristics and determination of major novel brominated flame retardants (NBFRs) in indoor dust," Analytical and Bioanalytical Chemistry, vol. 400, no. 9, pp. 3073-3083, 2011.

[79] M. J. La Guardia, R. C. Hale, E. Harvey, and D. Chen, "Flameretardants and other organohalogens detected in sewage sludge by electron capture negative ion mass spectrometry," Environmental Science \& Technology, vol. 44, no. 12, pp. 4658-4664, 2010.

[80] T. M. Kolic, L. Shen, K. MacPherson et al., "The analysis of halogenated flame retardants by GC-HRMS in environmental samples," Journal of Chromatographic Science, vol. 47, no. 1, pp. 83-91, 2009.

[81] H.-M. Park, S.-M. Hong, M. R. Agustin-Camacho, W. Dirwono, and K.-B. Lee, "Pressurized liquid extraction for the simultaneous analysis of polychlorinated biphenyls and polybrominated diphenyl ethers from soil by GC-TOF-MS detection," Journal of Chromatographic Science, vol. 47, no. 8, pp. 681-688, 2009.

[82] C. M. Medina, E. Pitarch, T. Portolés, F. J. López, and F. Hernández, "GC-MS/MS multi-residue method for the determination of organochlorine pesticides, polychlorinated biphenyls and polybrominated diphenyl ethers in human breast tissues," Journal of Separation Science, vol. 32, no. 12, pp. 20902102, 2009. 
[83] A. Ballesteros-Gómez, J. de Boer, and P. E. Leonards, "Novel analytical methods for flame retardants and plasticizers based on gas chromatography, comprehensive two-dimensional gas chromatography, and direct probe coupled to atmospheric pressure chemical ionization-high resolution time-of-flightmass spectrometry," Analytical Chemistry, vol. 85, pp. 95729580, 2013.

[84] S. J. Hur, B. O. Lim, E. A. Decker, and D. J. McClements, "In vitro human digestion models for food applications," Food Chemistry, vol. 125, no. 1, pp. 1-12, 2011.

[85] A. Kierkegaard, U. Sellström, and M. S. McLachlan, "Environmental analysis of higher brominated diphenyl ethers and decabromodiphenyl ethane," Journal of Chromatography A, vol. 1216, no. 3, pp. 364-375, 2009.

[86] S. J. Lupton, B. P. McGarrigle, J. R. Olson, T. D. Wood, and D. S. Aga, "Analysis of hydroxylated polybrominated diphenyl ether metabolites by liquid chromatography/atmospheric pressure chemical ionization tandem mass spectrometry," Rapid Communications in Mass Spectrometry, vol. 24, no. 15, pp. 22272235, 2010.

[87] R. J. Law, M. Kohler, N. V. Heeb et al., "Hexabromocyclododecane challenges scientists and regulators," Environmental Science \& Technology, vol. 39, no. 13, pp. 281A-287A, 2005.

[88] G. T. Tomy, T. Halldorson, R. Danell et al., "Refinements to the diastereoisomer-specific method for the analysis of hexabromocyclododecane," Rapid Communications in Mass Spectrometry, vol. 19, no. 19, pp. 2819-2826, 2005.

[89] M. A.-E. Abdallah, S. Harrad, C. Ibarra et al., "Hexabromocyclododecanes in indoor dust from Canada, the United Kingdom, and the United States," Environmental Science \& Technology, vol. 42, no. 2, pp. 459-464, 2008.

[90] D. Lankova, M. Kockovska, O. Lacina, K. Kalachova, J. Pulkrabova, and J. Hajslova, "Rapid and simple method for determination of hexabromocyclododecanes and other LCMS-MS-amenable brominated flame retardants in fish," Analytical and Bioanalytical Chemistry, vol. 405, no. 24, pp. 7829-7839, 2013.

[91] G. Arsenault, A. Konstantinov, C. H. Marvin et al., "Synthesis of the two minor isomers, delta- and epsilon-1, 2, 5, 6, 9, 10hexabromocyclododecane, present in commercial hexabromocyclododecane," Chemosphere, vol. 68, no. 5, pp. 887-892, 2007.

[92] W. Budakowski and G. Tomy, "Congener-specific analysis of hexabromocyclododecane by high-performance liquid chromatography/electrospray tandem mass spectrometry," Rapid Communications in Mass Spectrometry, vol. 17, no. 13, pp. 13991404, 2003.

[93] M. A.-E. Abdallah, S. Harrad, and A. Covaci, "Hexabromocyclododecanes and tetrabromobisphenol-A in indoor air and dust in Birmingham, UK: implications for human exposure," Environmental Science \& Technology, vol. 42, no. 18, pp. 68556861, 2008.

[94] B. Gómara, R. Lebrón-Aguilar, J. E. Quintanilla-López, and M. J. González, "Development of a new method for the enantiomer specific determination of HBCD using an ion trap mass spectrometer," Analytica Chimica Acta, vol. 605, no. 1, pp. 53-60, 2007.

[95] R. Cariou, J.-P. Antignac, P. Marchand et al., "New multiresidue analytical method dedicated to trace level measurement of brominated flame retardants in human biological matrices," Journal of Chromatography A, vol. 1100, no. 2, pp. 144-152, 2005.

[96] K. Janák, A. Covaci, S. Voorspoels, and G. Becher, "Hexabromocyclododecane in marine species from the Western Scheldt
Estuary: diastereoisomer- and enantiomer-specific accumulation," Environmental Science and Technology, vol. 39, no. 7, pp. 1987-1994, 2005.

[97] N. V. Heeb, W. B. Schweizer, M. Kohler, and A. C. Gerecke, "Structure elucidation of hexabromocyclododecanes-a class of compounds with a complex stereochemistry," Chemosphere, vol. 61, no. 1, pp. 65-73, 2005.

[98] Z. Yu, L. Chen, B. Mai et al., "Diastereoisomer- and enantiomerspecific profiles of hexabromocyclododecane in the atmosphere of an urban city in South China," Environmental Science \& Technology, vol. 42, no. 11, pp. 3996-4001, 2008.

[99] S. Harrad, M. A.-E. Abdallah, and A. Covaci, "Causes of variability in concentrations and diastereomer patterns of hexabromocyclododecanes in indoor dust," Environment International, vol. 35, no. 3, pp. 573-579, 2009.

[100] C. H. Marvin, G. MacInnis, M. Alaee, G. Arsenault, and G. T. Tomy, "Factors influencing enantiomeric fractions of hexabromocyclododecane measured using liquid chromatography/tandem mass spectrometry," Rapid Communications in Mass Spectrometry, vol. 21, no. 12, pp. 1925-1930, 2007.

[101] N. G. Dodder, A. M. Peck, J. R. Kucklick, and L. C. Sander, "Analysis of hexabromocyclododecane diastereomers and enantiomers by liquid chromatography/tandem mass spectrometry: chromatographic selectivity and ionization matrix effects," Journal of Chromatography A, vol. 1135, no. 1, pp. 3642, 2006.

[102] S. Morris, P. Bersuder, C. R. Allchin et al., "Determination of the brominated flame retardant, hexabromocyclodocane, in sediments and biota by liquid chromatography-electrospray ionisation mass spectrometry," Trends in Analytical Chemistry, vol. 25, no. 4, pp. 343-349, 2006.

[103] S. N. Zhou, E. J. Reiner, C. Marvin et al., "Liquid chromatography-atmospheric pressure photoionization tandem mass spectrometry for analysis of 36 halogenated flame retardants in fish," Journal of Chromatography A, vol. 1217, no. 5, pp. 633-641, 2010.

[104] S. Suzuki and A. Hasegawa, "Determination of hexabromocyclododecane diastereoisomers and tetrabromobisphenol A in water and sediment by liquid chromatography/mass spectrometry," Analytical Sciences, vol. 22, no. 3, pp. 469-474, 2006.

[105] P. Galindo-Iranzo, J. E. Quintanilla-López, R. Lebrón-Aguilar, and B. Gómara, "Improving the sensitivity of liquid chromatography-tandem mass spectrometry analysis of hexabromocyclododecanes by chlorine adduct generation," Journal of Chromatography A, vol. 1216, no. 18, pp. 3919-3926, 2009.

[106] M. S. Ross and C. S. Wong, "Comparison of electrospray ionization, atmospheric pressure photoionization, and anion attachment atmospheric pressure photoionization for the analysis of hexabromocyclododecane enantiomers in environmental samples," Journal of Chromatography A, vol. 1217, no. 50, pp. 7855-7863, 2010.

[107] L. W. Y. Yeung, Y. Miyake, S. Taniyasu et al., "Perfluorinated compounds and total and extractable organic fluorine in human blood samples from China," Environmental Science \& Technology, vol. 42, no. 21, pp. 8140-8145, 2008.

[108] P. Guerra, A. de La Torre, M. A. Martínez, E. Eljarrat, and D. Barceló, "Identification and trace level determination of brominated flame retardants by liquid chromatography/quadrupole linear ion trap mass spectrometry," Rapid Communications in Mass Spectrometry, vol. 22, no. 7, pp. 916-924, 2008.

[109] S. Chu, G. D. Haffner, and R. J. Letcher, "Simultaneous determination of tetrabromobisphenol A, tetrachlorobisphenol A, bisphenol $\mathrm{A}$ and other halogenated analogues in sediment and 
sludge by high performance liquid chromatography-electrospray tandem mass spectrometry," Journal of Chromatography A, vol. 1097, no. 1-2, pp. 25-32, 2005.

[110] G. L. Simon, D. M. Richmond, F. P. Tally, M. Barza, and S. L. Gorbach, "Penetration of clindamycin into experimental infections with Bacteroides fragilis," Journal of Antimicrobial Chemotherapy, vol. 8, no. 1, pp. 59-64, 1981.

[111] J. Tollbäck, C. Crescenzi, and E. Dyremark, "Determination of the flame retardant tetrabromobisphenol $\mathrm{A}$ in air samples by liquid chromatography-mass spectrometry," Journal of Chromatography A, vol. 1104, no. 1-2, pp. 106-112, 2006.

[112] R. Saint-Louis and E. Pelletier, "LC-ESI-MS-MS method for the analysis of tetrabromobisphenol $\mathrm{A}$ in sediment and sewage sludge," Analyst, vol. 129, no. 8, pp. 724-730, 2004.

[113] P. H. N. Oomen, G. D. Kant, R. P. F. Dullaart, W. D. Reitsma, and A. J. Smit, "Acute hyperglycemia and hyperinsulinemia enhance vasodilatation in type 1 diabetes mellitus without increasing capillary permeability and inducing endothelial dysfunction," Microvascular Research, vol. 63, no. 1, pp. 1-9, 2002.

[114] S. P. M. A. Oomen, P. B. van Hennik, C. Antonissen et al., "Somatostatin is a selective chemoattractant for primitive $\left(\mathrm{CD} 34^{+}\right)$hematopoietic progenitor cells," Experimental Hematology, vol. 30, no. 2, pp. 116-125, 2002.

[115] C. Marteau, S. Chevolleau, I. Jouanin et al., "Development of a liquid chromatography/atmospheric pressure photo-ionization high-resolution mass spectrometry analytical method for the simultaneous determination of polybrominated diphenyl ethers and their metabolites: application to BDE-47 metabolism in human hepatocytes," Rapid Communications in Mass Spectrometry, vol. 26, no. 6, pp. 599-610, 2012.

[116] K. Betts, "Discontinued pajama flame retardant detected in baby products and house dust," Environmental Science \& Technology, vol. 43, no. 19, p. 7159, 2009.

[117] M. A.-E. Abdallah and S. Harrad, "Modification and calibration of a passive air sampler for monitoring vapor and particulate phase brominated flame retardants in indoor air: application to car interiors," Environmental Science \& Technology, vol. 44, no. 8, pp. 3059-3065, 2010.

[118] M. A. Abdallah and S. Harrad, "Polybrominated diphenyl ethers in UK human milk: implications for infant exposure and relationship to external exposure," Environment International, vol. 63, pp. 130-136, 2014.

[119] S. N. Zhou, E. J. Reiner, C. Marvin et al., "Development of liquid chromatography atmospheric pressure chemical ionization tandem mass spectrometry for analysis of halogenated flame retardants in wastewater," Analytical and Bioanalytical Chemistry, vol. 396, no. 3, pp. 1311-1320, 2010.

[120] G. Mascolo, V. Locaputo, and G. Mininni, "New perspective on the determination of flame retardants in sewage sludge by using ultrahigh pressure liquid chromatography-tandem mass spectrometry with different ion sources," Journal of Chromatography A, vol. 1217, no. 27, pp. 4601-4611, 2010.

[121] R. J. Letcher and S. Chu, "High-sensitivity method for determination of tetrabromobisphenol-S and tetrabromobisphenolA derivative flame retardants in great lakes herring gull eggs by liquid chromatography-atmospheric pressure photoionizationtandem mass spectrometry," Environmental Science \& Technology, vol. 44, no. 22, pp. 8615-8621, 2010.

[122] G. Qu, A. Liu, T. Wang et al., "Identification of tetrabromobisphenol A allyl ether and tetrabromobisphenol A 2,3-dibro- mopropyl ether in the ambient environment near a manufacturing site and in mollusks at a coastal region," Environmental Science \& Technology, vol. 47, no. 9, pp. 4760-4767, 2013.

[123] G. Arsenault, A. Lough, C. Marvin et al., "Structure characterization and thermal stabilities of the isomers of the brominated flame retardant 1,2-dibromo-4-(1,2-dibromoethyl)cyclohexane," Chemosphere, vol. 72, no. 8, pp. 1163-1170, 2008.

[124] S. Harrad, M. A.-E. Abdallah, N. L. Rose, S. D. Turner, and T. A. Davidson, "Current-use brominated flame retardants in water, sediment, and fish from English lakes," Environmental Science \& Technology, vol. 43, no. 24, pp. 9077-9083, 2009.

[125] B. N. Zegers, A. Mets, R. van Bommel et al., "Levels of hexabromocyclododecane in harbor porpoises and common dolphins from Western European seas, with evidence for stereoisomerspecific biotransformation by cytochrome P450," Environmental Science \& Technology, vol. 39, no. 7, pp. 2095-2100, 2005.

[126] S. H. Brandsma, L. T. M. van der ven, J. de Boer, and P. E. G. Leonards, "Identification of hydroxylated metabolites of hexabromocyclododecane in wildlife and 28-days exposed Wistar rats," Environmental Science and Technology, vol. 43, no. 15, pp. 6058-6063, 2009.

[127] S. Esslinger, R. Becker, R. Maul, and I. Nehls, "Hexabromocyclododecane enantiomers: microsomal degradation and patterns of hydroxylated metabolites," Environmental Science \& Technology, vol. 45, no. 9, pp. 3938-3944, 2011.

[128] M. Sagmeister, M. Postl, U. Brossmann et al., "Structure and electrical properties of nanoparticulate tungsten oxide prepared by microwave plasma synthesis," Journal of Physics Condensed Matter, vol. 23, no. 33, Article ID 334206, 2011.

[129] R. Song, Y. He, M. B. Murphy et al., "Effects of fifteen PBDE metabolites, DE71, DE79 and TBBPA on steroidogenesis in the H295R cell line," Chemosphere, vol. 71, no. 10, pp. 1888-1894, 2008.

[130] Y. Yu, W. Yang, Z. Gao et al., "RP-HPLC measurement and quantitative structure-property relationship analysis of the $n$ octanol-water partitioning coefficients of selected metabolites of polybrominated diphenyl ethers," Environmental Chemistry, vol. 5, no. 5, pp. 332-339, 2008.

[131] Y. Kato, S. Okada, K. Atobe et al., "Simultaneous determination by APCI-LC/MS/MS of hydroxylated and methoxylated polybrominated diphenyl ethers found in marine biota," Analytical Chemistry, vol. 81, no. 14, pp. 5942-5948, 2009.

[132] M. L. Feo, E. Barón, D. S. Aga, E. Eljarrat, and D. Barceló, "Development of a liquid chromatography-electrospray chemical ionization tandem mass spectrometry analytical method for analysis of eleven hydroxylated polybrominated diphenyl ethers," Journal of Chromatography A, vol. 1301, pp. 80-87, 2013.

[133] Q. Ma, C. Wang, H. Bai et al., "Comprehensive two-dimensional separation of hydroxylated polybrominated diphenyl ethers by ultra-performance liquid chromatography coupled with ion mobility-mass spectrometry," Journal of the American Society for Mass Spectrometry, vol. 22, no. 10, pp. 1851-1861, 2011.

[134] P. Patel, H. Mulla, V. Kairamkonda et al., "Dried blood spots and sparse sampling: A practical approach to estimating pharmacokinetic parameters of caffeine in preterm infants," British Journal of Clinical Pharmacology, vol. 75, no. 3, pp. 805-813, 2013. 

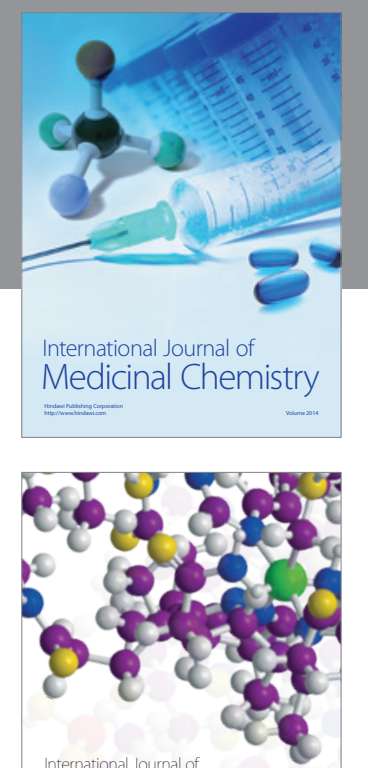

\section{Carbohydrate} Chemistry

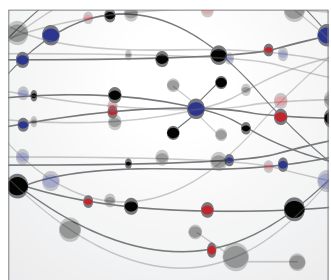

The Scientific World Journal
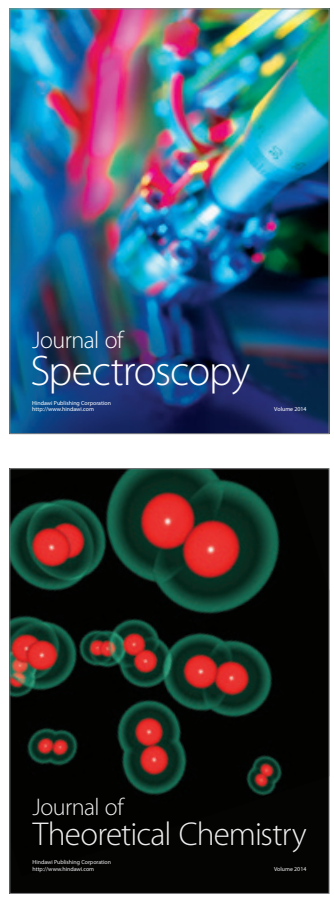
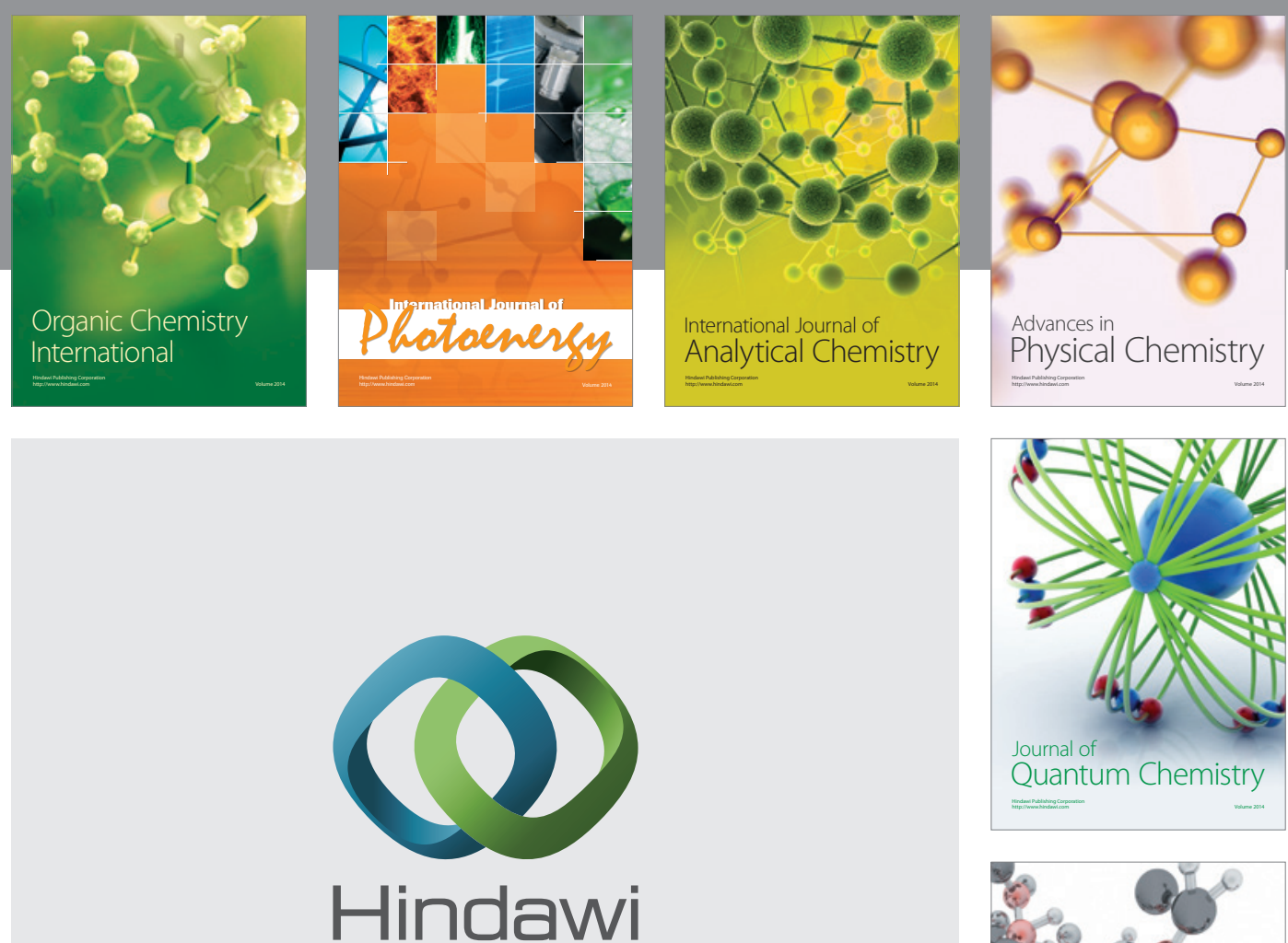

Submit your manuscripts at

http://www.hindawi.com

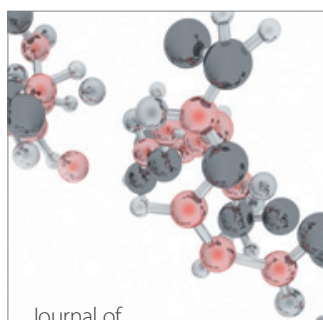

Analytical Methods

in Chemistry

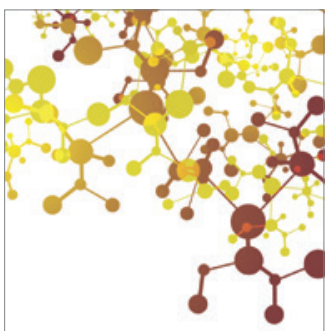

Journal of

Applied Chemistry

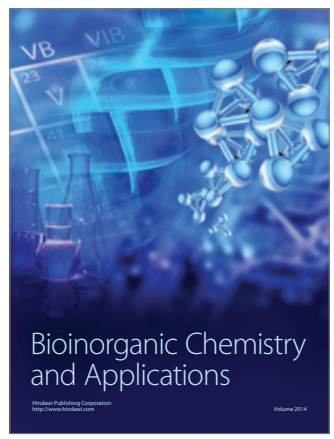

Inorganic Chemistry
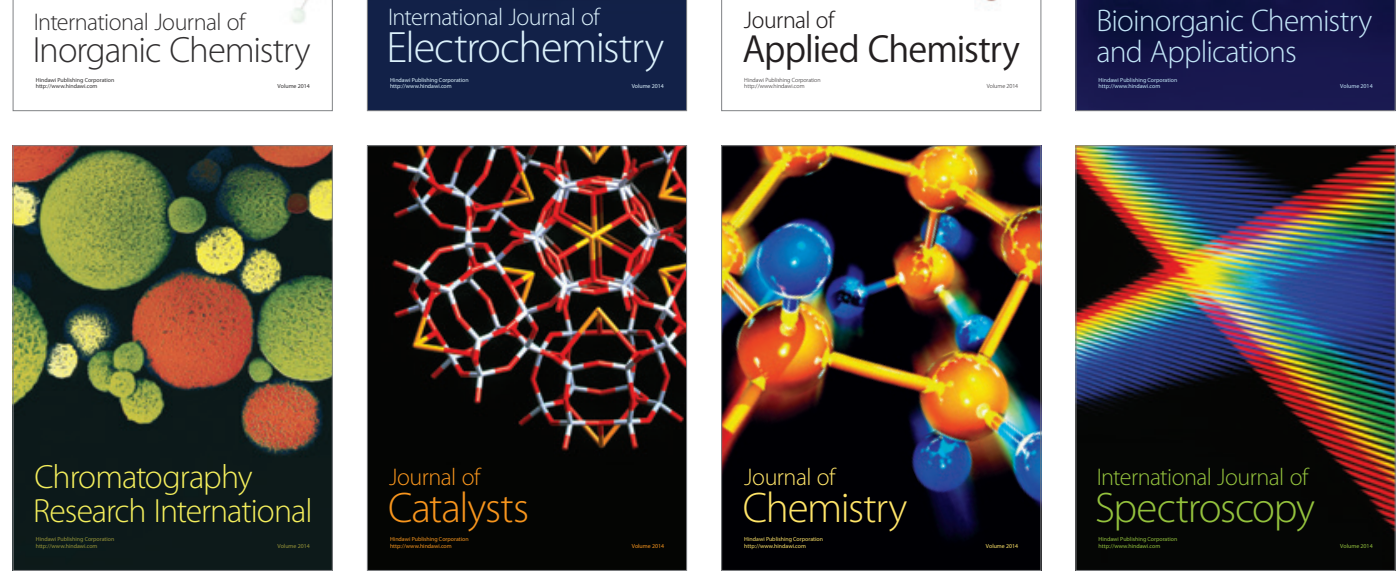